\title{
Thermodynamic Analysis and Performance Optimization of Organic Rankine CyCles for the Conversion of LoW-TO-Moderate Grade Geothermal HEAT
}

\author{
${ }^{1}$ Yekoladio, P.J., ${ }^{1 *}$ Bello-Ochende, T. and ${ }^{2}$ Meyer J.P. \\ ${ }^{1}$ Department of Mechanical Engineering, University of Cape Town, Private Bag X3, \\ Rondebosch, 7701, South Africa. \\ ${ }^{2}$ Department of Mechanical and Aeronautical Engineering, University of Pretoria, Pretoria \\ Private Bag X20, Hatfield 0028, South Africa.
}

\begin{abstract}
The present study considers a thermodynamic analysis and performance optimization of geothermal power cycles. The proposed binary-cycles operate with moderately low temperature and liquid-dominated geothermal resources in the range of $110^{\circ} \mathrm{C}$ to $160^{\circ} \mathrm{C}$, and cooling air at ambient conditions of $25^{\circ} \mathrm{C}$ and $101.3 \mathrm{kPa}$ reference temperature and atmospheric pressure, respectively. A thermodynamic optimization process and irreversibility analysis were performed to maximize the power output while minimizing the overall exergy destruction and improving the First- and Second-law efficiencies of the cycle. Maximum net power output was observed to increase exponentially with the geothermal resource temperature to yield $16-49 \mathrm{~kW}$ per unit mass flow rate of the geothermal fluid for the nonregenerative ORCs, as compared to $8-34 \mathrm{~kW}$ for the regenerative cycles. The cycle First-law efficiency was determined in the range of $8-15 \%$ for the investigated geothermal binary power cycles. Maximum Second-law efficiency of approximately $56 \%$ was achieved by the ORC with an IHE. In addition, a performance analysis of selected pure organic fluids such as $\mathrm{R} 123, \mathrm{R} 152 \mathrm{a}$, isobutane and n-pentane, with boiling points in the range of $-24^{\circ} \mathrm{C}$ to $36^{\circ} \mathrm{C}$, was conducted under saturation temperature and subcritical pressure operating conditions of the turbine. Organic fluids with higher boiling point temperature, such as n-pentane, were recommended for non-regenerative cycles. The regenerative ORCs, however, require organic fluids with lower vapour specific heat capacity (i.e. isobutane) for an optimal operation of the binary-cycle.
\end{abstract}

\footnotetext{
* Corresponding author. Tel.: +27 21650 3673; Fax: +27 216503240
}

Email address: tunde.bello-ochende@uct.ac.za 
KEYWORDS: geothermal energy, organic Rankine cycle, optimization, irreversibility analysis, exergy.

\section{Nomenclature}

\section{Alphabetic symbols}

$\mathrm{Cp} \quad$ Specific heat capacity, $\mathrm{J} / \mathrm{kg} . \mathrm{K}$

$\dot{E} x \quad$ Exergy rate, $\mathrm{W}$

$h \quad$ Enthalpy, $\mathrm{kJ} / \mathrm{kg}$

I $\quad$ Exergy destruction, $\mathrm{W}$

$L \quad$ Latent heat, $\mathrm{kJ} / \mathrm{kg}$

$\dot{m} \quad$ Mass flow rate, $\mathrm{kg} / \mathrm{s}$

$P \quad$ Pressure, $\mathrm{Pa}$

$\dot{Q} \quad$ Heat transfer rate, $\mathrm{W}$

$s \quad$ Specific entropy, J/kg.K

T Temperature, ${ }^{\circ} \mathrm{C}$

$\dot{W} \quad$ Power output, W

\section{Abbreviations}

ATL Atmospheric Lifetime

GWP Global Warming Potential

HC Hydrocarbons

HCFC Hydrochlorofluorocarbons

HFC Hydrofluorocarbons

IHE Internal Heat Exchanger

O\&M Operating and Maintenance

ODP Ozone Depletion Potential

OFOH Open Feed Organic Heater

ORC Organic Rankine Cycle

PH Preheater

\section{Greek symbols}

$\delta \quad$ Fuel depletion ratio

$\varepsilon \quad$ Effectiveness, \%

$\eta_{I} \quad$ First Law efficiency, \% 
$\eta_{I I} \quad$ Second Law efficiency, $\%$

$v \quad$ Vapour

$\psi \quad$ Specific exergy, $\mathrm{J} / \mathrm{kg}$

\section{Subscripts}

$0 \quad$ Reference state

1-15 Thermodynamic states

bp Boiling point

c Condenser

cr Critical value

CS Cooling system

dest Destruction

E Evaporator

ext Extraction

geo Geothermal fluid

$H E$ Heat exchanger

in Inlet

$\max$ Maximum

min Minimum

net Net

opt Optimum

out Outlet

$p \quad$ Circulation pump

$p p \quad$ Pinch-point

rej Reinjection

$s \quad$ Isentropic

$t \quad$ Turbine

th Thermal

$v \quad$ Vapour

$w f \quad$ Working fluid 


\section{Introduction}

The present study considers a thermodynamic analysis and performance optimization of organic Rankine cycles (ORC) for the conversion of low-to-moderate grade geothermal heat. The proposed energy conversion systems, known as binary-cycles, operate with moderately low temperature and liquid-dominated geothermal resources in the range of $110^{\circ} \mathrm{C}$ to $160^{\circ} \mathrm{C}$, and cooling air at ambient conditions of $25^{\circ} \mathrm{C}$ and $101.3 \mathrm{kPa}$ reference temperature and atmospheric pressure, respectively. A thermodynamic optimization process of the proposed binary-cycles was based on the irreversibility analysis to maximize the power output, while minimizing the overall exergy destruction and improving the First- and Second-law efficiencies of the cycle.

Various studies have been conducted in this regard. Among others, we may acknowledge Kanoglu [1] who directed his focus to the performance evaluation of an existing 12.4 MW dual-level binary geothermal power plant, and revealed significant fraction of exergy destruction occurring in the condenser, the reinjection process of the brine, the turbine-pump assembly and the preheater-vaporizer. These accounted for 22.6, 14.8, 13.9 and $13.0 \%$ of the total exergy input to the plant, respectively. Yari [2] confirmed that more than $51 \%$ of the exergy input from high-temperature geothermal resources was lost.

The First- and Second-law efficiencies were also quantified by many other researchers based on either the energy or exergy input into the power generating cycle. The study on flashsteam cycles by Bodvardson and Eggers [3], yielded an exergetic efficiency of $38.7 \%$ and $49 \%$ for the single-flash and double-flash cycle, respectively, based on $250^{\circ} \mathrm{C}$ resource water temperature and $40^{\circ} \mathrm{C}$ sink temperature. Binary Rankine cycles were rated, by Kanoglu and Bolatturk [4] at 5-15\% and 20-54\% First- and Second-law efficiency, respectively. Franco [5] approximated the First- and Second-law efficiencies of the geothermal binary power plants in the range of $5-10 \%$ and $25-45 \%$, respectively, resulting to large heat transfer surfaces for both the heat recovery and condensation systems. DiPippo [6] suggested that binary plants, which operate with low temperature and/or low exergy geothermal resources, could achieve $40 \%$ or higher exergetic efficiencies with geothermal fluids having specific exergies of $200 \mathrm{~kJ} / \mathrm{kg}$ or lower. He concluded that the higher exergetic efficiency was a result of primarily, the optimum design of the heat exchangers to minimize the destruction of exergy during the heat transfer processes and secondarily, the availability of low temperature cooling water to allow a once-through system for waste heat rejection. 
The choice of the working fluids was found to be crucial to the design and performance of the geothermal power plants, to the extent of significantly affecting both the power plant capital cost and the cost of operation and maintenance (O\&M) [7].

Various other studies were conducted by diverse authors proposing innovative methods to improve the performance of the binary-cycle geothermal power plants, which operate with moderately low temperature geothermal resources. Kanoglu [1] discussed a dual-level binary geothermal power plant, Gu and Sato [8] studied the supercritical cycles, while DiPippo [9] proposed a recovery heat exchanger (RHE) with a cascade of evaporators, and high/low pressure turbines operating in a Kalina cycle. Desai and Bandyopadhyay [10] recommended incorporating both regeneration and turbine bleeding to the basic organic Rankine cycles, whereas Gnutek and Bryszewska-Mazurek [11] suggested multicycle with different thermodynamic properties.

An investigation on the optimal design of the binary cycle power plants for maximum power output was discussed by Borsukiewicz-Gozdur and Novak [12] who maximized the working fluid flow to increase the power output of the geothermal power plant while repeatedly returning a fraction of the geothermal fluid downstream of the evaporator to completely vaporize the working fluid prior expanding in the turbine. Madhawa et al [7] presented a costeffective optimum design criterion based on the ratio of total heat transfer area to the net power output, as the objective function, for the basic ORC employing low temperature geothermal resources.

In most of the studies mentioned above, the minimization of the geothermal fluid flow rate (or specific brine consumption) for a given net power output was addressed as the objective function for the optimum design of the ORCs. The present study, however, focuses on maximizing the power output for a given geothermal fluid flow rate while minimizing the overall exergy destruction and improving the First- and Second-law efficiencies of the cycle.

In addition, the authors have performed an analytical and numerical thermodynamic optimization of the proposed ORCs to significantly reduce the irreversibilities due to heat transfer and fluid friction caused by the cycle components. Furthermore, a performance analysis of pure organic fluids such as R123, R152a, isobutane and n-pentane, with boiling points in the range of $-24^{\circ} \mathrm{C}$ to $36^{\circ} \mathrm{C}$, was conducted to demonstrate the extent at which they affect the design and operation of the binary geothermal power plants, which operate under saturation temperature and subcritical pressure operating conditions of the turbine. 


\section{Proposed model}

Small binary cycle geothermal power plants operating with moderate low grade and liquiddominated geothermal resources in the range of $110^{\circ} \mathrm{C}$ to $160^{\circ} \mathrm{C}$ and cooling air at ambient conditions of $25^{\circ} \mathrm{C}$ and $101.3 \mathrm{kPa}$ reference temperature and atmospheric pressure, respectively, were considered. The low grade geothermal heat is suitably recovered by either an ORC or a Kalina cycle. For the purpose of this study, the ORC was preferred considering its extensive use in geothermal power generation, the simplicity of its power cycle, and the ease of maintenance [13].

In the literature, more than 50 pure and mixtures of organic compounds for ORC have been considered. These have been classified as "wet", "dry" or "isentropic" organic fluids according to the slope of its saturated-vapour line [13]. The behaviour of pure organic fluids with boiling points in the range of $-24^{\circ} \mathrm{C}$ to $36^{\circ} \mathrm{C}$, such as $\mathrm{R} 123, \mathrm{R} 152 \mathrm{a}$, isobutane and $\mathrm{n}$ pentane, were investigated to assess their thermodynamic performance as binary organic fluids for the conversion of the low-to-moderate grade geothermal heat.

Refrigerant R123 is an isentropic organic fluid with a near-vertical saturated vapour-phase line, thus a nearly infinitely large slope of the saturated-vapour line. Refrigerant R152a belongs to the wet type, thus has a negative slope of the saturated-vapour line. Isobutane and n-pentane are dry organic compounds, and are characterized by a positive slope of the saturated-vapour line.

For subcritical pressure processes, dry organic compounds are usually preferred since the expansion process in the turbine ends in the superheated region. Isentropic fluids however, having a near-vertical saturated-vapour line, lead to saturated vapour at the later stages of the turbine, whereas wet fluids form a mixture of liquid and vapour, and thus require superheating to avoid the risk of the turbine blades erosion [14].

In Table 1, the main thermo-physical properties of the investigated pure organic fluids are listed, as obtained from the Engineering Equation Solver (EES) software [15]. High latent heat of vaporization can be observed for dry fluids (i.e. n-pentane and isobutane), moderate value for the wet organic fluid R152a, and low latent heat of vaporization for the isentropic fluid, R123. Based on the critical temperature and with reference to the Celsius scale, positive normal boiling point temperatures were observed for R123 and n-pentane as compared to negative normal boiling point temperatures for $\mathrm{R} 152 \mathrm{a}$ and isobutane. Considering the 
environmental impacts of the investigated pure organic fluids, dry organic compounds have revealed favourable ozone depletion potential (ODP), global warming potential (GWP) and atmospheric lifetime (ATL). In summary, the choice of dry organic compounds as optimal organic fluids for the conversion of low grade energy resources is justified as a result of their excellent thermodynamic properties and nearly clean environmental impact characteristics.

Four types of ORCs were assessed analytically and numerically, and their performance optimized to maximize the power output. The proposed ORCs are illustrated in Fig. 1. In Fig. 1a, a basic type of an ORC is pictured. A primary heat transfer medium is pumped, continuously circulated and heated by the linearly increasing underground temperature with depth. The geothermal fluid flows down the annular space of a downhole coaxial heat exchanger of an enhanced geothermal system (EGS) [2,16]. The coaxial pipes dimensions and fluid circulation flow rate were optimized by Yekoladio et al. [17] for minimum pumping power and maximum extracted heat energy from the Earth's deep underground. The warmer geothermal fluid is used to completely vaporize a secondary or binary fluid with a lower boiling point and higher vapour pressure through a closed pipe system heat exchanger. The binary fluid is thereafter allowed to expand in a turbine and condensed either in an air-cooled or water-cooled condenser prior returning to the vaporizer and thus completing the Rankine cycle [4]. If the expansion process in the turbine terminates in the superheated region, a heat recuperator (or internal heat exchanger, IHE) can be advantageous to preheat the binary fluid prior evaporation. In this manner, the evaporator load is significantly reduced, and the efficiency of the cycle is extensively improved (Fig. 1b) $[18,19]$.

Further improvement on the heat exchange performance and the Rankine cycle overall efficiency can be achieved with the addition of a two-phase regenerative cycle $[2,10]$. The latter utilizes an open feed-heater to preheat the binary fluid prior evaporation with the extracted fluid from the turbine expanded vapour (Fig. 1c). A combination of a regenerator and recuperator can also be employed to improve the performance of the heat exchange process (Fig. 1d) [2].

The cycles' temperature versus entropy diagrams are illustrated in Fig. 2. For the basic ORC (Fig. 2a), steps 1-2 and 4-5 refer to non-isentropic pumping and expansion processes under adiabatic operating conditions, respectively. On the other hand, steps 2-3 and 5-1 represent constant-pressure heat addition and rejection, respectively. The addition of an IHE to the basic ORC is represented by states 3 and 7 in Fig. 2 b. 
In contrast to the non-regenerative types of ORCs, the regenerative cycle consists of three constant-pressure heat transfer processes (Fig. 2c). Ideally, the mixture of the turbine bleeding and the condensate at the exit of the open feed-organic heater is assumed at saturated liquid condition and at the evaporator pressure [20]. The addition of an IHE to the regenerative ORC is illustrated by states 3 and 10 in Fig. 2d.

Many other power cycles have been proposed and studied in the literature aiming at improving the performance of the binary-cycle power plant for the conversion of low-tomoderate grade heat resources. Among others, we may acknowledge a heat recovery cycle with a high and low pressure turbine or multiple pressure levels [1], a heat recovery exchanger with a cascade of evaporators employed in a Kalina cycle [6], a supercritical Rankine cycle [8], a trilateral flash and the Goswami cycles [21].

\section{Research methodology}

\subsection{Energy and exergy analysis}

Mass, energy, and exergy balances for individual control volume at steady state with negligible potential and kinetic energy changes can be expressed, respectively, by $[2,4,19]$

$$
\begin{aligned}
& \sum \dot{m}_{\text {in }}=\sum \dot{m}_{\text {out }} \\
& \dot{Q}-\dot{W}=\sum \dot{m}_{\text {out }} h_{\text {out }}-\sum \dot{m}_{\text {in }} h_{\text {in }} \\
& \dot{E} x_{\text {heat }}-\dot{W}+\sum \dot{m}_{\text {in }} \psi_{\text {in }}-\sum \dot{m}_{\text {out }} \psi_{\text {out }}=\dot{I}
\end{aligned}
$$

Where

$$
\dot{E} x_{\text {heat }}=\sum\left(1-\frac{T_{o}}{T_{j}}\right) \dot{Q}_{j}
$$

The subscript " $j$ " refers to the different states of the heat transfer process as it occurs.

The flow specific exergy was defined as

$$
\psi=\left(h-h_{o}\right)-T_{o}\left(s-s_{o}\right)
$$

The net power output was determined by, [19]

$$
\dot{W}_{n e t}=\dot{W}_{t}+\dot{W}_{p}
$$

And the total exergy lost in the cycle and plant were defined respectively by $[4,19]$

$$
\begin{aligned}
& \dot{I}_{\text {cycle }}=\sum_{\text {all components }} \dot{I}_{i}=\dot{I}_{p}+\dot{I}_{H E s}+\dot{I}_{t}+\dot{I}_{c} \\
& \dot{I}_{\text {plant }}=\dot{I}_{\text {cycle }}+\dot{I}_{r e j}+\dot{I}_{C S}=\dot{E} x_{i n}-\dot{W}_{n e t}
\end{aligned}
$$

Where the total exergy inputs to the ORC was determined by $[1,4,6,13]$ 


$$
\dot{E} x_{i n}=\dot{m}_{g e o}\left[\left(h_{g e o}-h_{o}\right)-T_{o}\left(s_{g e o}-s_{o}\right)\right]
$$

\subsection{Performance analysis}

The First- and Second-law efficiencies, based on the geothermal fluid state at the inlet of the primary heat exchanger and with respect to the reference temperature $T_{o}$, were defined respectively as $[1,4,6]$

$$
\begin{aligned}
& \eta_{I}=\frac{\text { net work output }}{\text { total energy inputs }}=\frac{\dot{W}_{\text {net }}}{\dot{m}_{\text {geo }}\left(h_{\text {geo }}-h_{o}\right)} \\
& \eta_{I I}=\frac{\text { net work output }}{\text { total exergy inputs }}=\frac{\dot{W}_{\text {net }}}{\dot{m}_{\text {geo }}\left[\left(h_{\text {geo }}-h_{o}\right)-T_{o}\left(s_{\text {geo }}-s_{o}\right)\right]}
\end{aligned}
$$

Based on the energy and exergy input to the cycle, the First- and Second-law efficiency were given by $[1,4,6]$

$$
\begin{aligned}
& \eta_{I, 2}=\frac{\dot{W}_{\text {net }}}{\dot{m}_{\text {geo }}\left(h_{\text {geo }}-h_{r e j}\right)}=\frac{\dot{W}_{\text {net }}}{\dot{m}_{w f}\left(h_{w f, o u t}-h_{w f, i n}\right)} \\
& \eta_{I I, 2}=\frac{\dot{W}_{\text {net }}}{\dot{m}_{\text {geo }}\left[\left(h_{\text {geo }}-h_{r e j}\right)-T_{o}\left(s_{\text {geo }}-s_{r e j}\right)\right]}
\end{aligned}
$$

The performance of a binary-cycle geothermal power plant can also be evaluated using the cycle effectiveness, which represents the effectiveness of heat transfer to the cycle from the geothermal fluid, as $[1,4,6,13]$

$$
\varepsilon=\frac{\dot{W}_{\text {net }}}{\dot{m}_{w f}\left[\left(h_{w f, \text { out }}-h_{w f, \text { in }}\right)-T_{o}\left(s_{w f, \text { out }}-s_{w f, \text { in }}\right)\right]}
$$

As discussed by Subbiah and Natarajan [13], the First-law efficiency is a quantitative measure of the effectiveness of the conversion of the available geothermal energy into useful work. The Second-law efficiency accounts for the overall exergy inputs to the cycle between the geothermal fluid temperature at the outlet of the resource well and the reference temperature $T_{o}$. The cycle effectiveness, on the other hand, measures both quantitatively and qualitatively the fraction of available energy to be transferred into useful work.

The performance analysis of individual component of the cycle was evaluated using the fuel depletion ratio, which was defined by $[2,22]$ :

$$
\delta_{i}=\frac{\dot{I}_{i}}{\dot{E} x_{i n}}
$$




\subsection{Irreversibility analysis}

In Fig. 3a, the exergy destruction (irreversibility) associated with the heat transfer process occurring in the evaporator-preheater unit is represented by the marked area of the temperature versus heat transfer diagram, assuming linearity of the geothermal fluid cooling curve. The significant exergy destruction is a consequence of the large difference in temperature between the geothermal and the binary fluids [23]. The addition of an IHE to the basic ORC is demonstrated to reduce the irreversibility of the heat transfer process as the working fluid was preheated prior entering the preheater (Fig. 3b). A decrease in irreversibility can also be achieved while utilizing a regenerative Rankine cycle to improve the heat exchange performance (Fig. 3c). Further reduction in irreversibility is possible with a combination of a regenerator and recuperator (Fig. 3d).

\subsection{Optimization procedure and model validation}

This paper consists of an analytical and numerical thermodynamic optimization of organic Rankine cycles (ORC). The optimization process and irreversibility analysis were performed to minimize the overall exergy destruction of the power plant, as well as the irreversibilities associated with heat transfer and fluid friction caused by the system components.

For a given thermodynamic cycle and pure organic fluid, the optimal operating conditions of the binary-cycle were determined using the steepest descent method. As illustrated in the simulation flow chart shown in Fig. 4, the minimization of the overall exergy destruction of the power plant and the irreversibilities associated with heat transfer and fluid friction was performed to maximize the First- and Second-law efficiency. The evaporative and condensation operating conditions of the binary-cycles were optimized under saturation temperature and subcritical pressure operating conditions of the turbine. The plant configuration was therefore optimized and the net power output maximized per unit mass flow rate of the geothermal fluid.

The thermodynamic performance of the proposed ORCs was analysed using EES software [15]. The numerical data were validated with available data published in the open literature for refrigerant R123, at the operating conditions listed in Table 2. The comparison shown in Table 3 illustrates a very good agreement between the present work and the results of Yari $[2]$. 


\section{Results and discussion}

\subsection{Thermodynamic performance of organic binary fluids}

A thermodynamic performance of the investigated pure organic fluids was considered for the basic and regenerative ORCs. The pinch-point and condensation temperatures were fixed at $5^{\circ} \mathrm{C}$ and $40^{\circ} \mathrm{C}$, respectively, while the turbine inlet temperature was varied from the limiting temperature of condensation to the geofluid input temperature.

In Fig. 5, the variation of the net power output per unit mass flow rate of the geofluid was plotted for both configurations at subcritical pressure operating conditions. For the basic ORC, the investigated pure organic fluids demonstrated a merely identical behaviour at the studied operating conditions (Fig. 5a). However, the lower the boiling point temperature of the organic fluid, the higher the evaporating temperature in the studied range of heat source temperature. On the other hand, an optimal turbine inlet temperature and maximum net power output per unit mass flow of the geothermal fluid significantly differed for the regenerative ORC (Fig. 5b), depending on the thermodynamic properties of the organic fluids to behave with a fixed optimum turbine extraction pressure determined by Yari [2].

While a nearly identical thermodynamic performance was noted for isobutane, the ability to convert the total exergy input into useful work output was observed to be reduced substantially by as much as $15 \%, 26 \%$ and $42 \%$ for refrigerants R152a, R123 and n-pentane, respectively. Thus, the supremacy of organic fluids with low vapour specicific heat capacity, such as isobutane, to convert low-to-moderate geothermal resource temperature at relatively low evaporating temperature is remarkably demonstrated for the regenerative configuration. For other organic fluids, the advantage of adding an $\mathrm{OFOH}$ to improve the heat exchange performance of the binary cycle is offset by the increase in the overall plant irreversibility. This results from a substantial increase in the rejection exergy destruction back to the exploitation reservoir, as also proven by Yari [2]. Furthermore, the reduction in the power output can also be attributed to the increase in the turbine inlet temperature which is a consequence of an increase in the enthalpy of the inlet fluid to the turbine and a decrease in the flow rate of the binary fluid, as explicitly discussed by Lakew and Bolland [24].

A similar conclusion can also be drawn for the First- and Second-law efficiencies (Eqs. 10 and 11) with respect to the reference temperature $T_{o}$, as illustrated in Fig. 6. 
In Figs. 7 and 8, the variation of the First- and Second-law efficiencies (Eqs. 12 and 13) with the turbine inlet temperature, and based on energy and exergy input to the ORC, were illustrated. No extremum was, however, observed. The organic fluids with high boiling point temperature, such as R123 and n-pentane, had the best performance among the investigated pure organic fluids for both configurations. Furthermore, the regenerative ORC was observed to yield high First- and Second-law efficiency, based on energy and exergy input to the ORC, at higher turbine inlet temperatures as compared to the basic cycle.

Likewise, the cycle effectiveness, which measures both quantitatively and qualitatively the fraction of available energy to be transferred from the geothermal resource to the organic binary fluid was plotted in Fig. 9, as a function of the turbine inlet temperature. For the basic ORC (Fig. 9a), only a marginal difference in the cycle effectiveness was observed between the investigated pure organic fluids. For the regenerative ORC (Fig. 9b), however, isobutane showed better performance at low operating temperature of the turbine, whereas R123 and npentane demonstrated better conversion of the thermal energy at high turbine inlet temperatures.

Hence, for the conversion of low-to-moderate grade geothermal heat, organic fluids with high boiling point temperature, such as n-pentane, would be highly recommended for the basic configuration, in consistency with the result proposed by Mago et al. [20]. On the other hand, organic fluids with lower vapour specific heat capacity, such as isobutane, would be more suitable for the regenerative ORC. Nevertheless, one should also consider the chemical stability and compatibility of the organic fluids with the materials, the environmental impacts, the safety concerns, and the economical operation of the binary fluids [14,25-27] for the selection of an optimal organic fluid suitable for the conversion of low-to-moderate geothermal heat.

\subsection{Performance evaluation of organic Rankine cycles}

\subsubsection{Energy and exergy analysis}

In Fig. 10, the First- and Second-law efficiencies (Eqs. 10 and 11) were plotted based on the reference temperature $T_{o}$. An optimal turbine inlet temperature was observed to maximize both the First- and Second-law efficiencies. The regenerative ORCs were observed to be less efficient as compared to the non-regenerative cycles considering the effectiveness of the conversion of the available geothermal energy and exergy into useful work. 
In Fig. 11, the First- and Second-law efficiencies (Eqs. 12 and 13) were plotted based on the energy and exergy input to the cycle, respectively. At low turbine inlet temperatures, the nonregenerative cycles were observed to be more efficient than the regenerative ORCs. However, as the turbine inlet temperature increased, the addition of both an OFOH and IHE has proven to significantly improve the First- and Second-law efficiencies based on the energy and exergy input to the cycle, respectively, as compared to the basic ORC. This could be attributed to the ability of the regenerative cycles to minimize the exergy destruction (irreversibility) during the heat transfer process. Furthermore, the noticeable low First-law efficiency of the geothermal energy (Fig. 11a) is mostly attributed to the low temperature of the geothermal resource.

The cycle effectiveness was plotted in Fig. 12 as a function of the turbine inlet temperature. The Second-law efficiency with respect to the exergy input to the cycle, and the cycle effectiveness as illustrated in Figs. $11 \mathrm{~b}$ and 12, respectively, were observed to yield an optimal turbine inlet temperature beyond which no substantial increase in both the Secondlaw efficiency with respect to the exergy input to the cycle, and cycle effectiveness was possible.

\subsubsection{Irreversibility analysis}

An irreversibility analysis was conducted using the overall plant irreversibility as the objective function. It was defined as the sum of the exergy destruction in each component of the cycle. In Fig. 13, the overall plant irreversibility was plotted against the turbine inlet temperature. An optimal turbine inlet temperature was observed to yield minimum overall plant irreversibility, which also produced maximum First- and Second-law efficiencies with respect to the reference temperature $T_{o}$.

The ratio of the exergy destruction of the individual component to the total exergy input to the ORC was defined by the fuel depletion ratio. In Fig. 14, the latter was plotted as a function of the turbine inlet temperature. Within the range of the geothermal fluid temperature investigated in this study, the addition of an IHE to the binary cycle resulted in a significant reduction of approximately $1-5 \%$ in the overall cycle fuel depletion ratio due to primarily the decrease in the rate of exergy destruction in the evaporator-preheater unit. Adding an OFOH to the binary cycle, on the other hand, resulted in a remarkable reduction of the rate of exergy destruction in all individual components of the binary cycle to account for nearly 3-7\% decrease in the overall cycle fuel depletion ratio. The major sites of exergy 
destruction were observed in the condenser and turbine, which accounted for up to $5 \%$ and $3 \%$, respectively, within the range of the geothermal fluid temperature investigated in this study. The addition of both IHE and OFOH yielded a combined reduction not exceeding $10 \%$ in the overall cycle fuel depletion ratio.

\subsubsection{Performance analysis}

In Fig. 15, the net power output per unit mass flow rate of the geothermal fluid was plotted against the turbine inlet temperature. As discussed by Lakew and Bolland [27], the increase in the turbine inlet temperature resulted in an increase in the enthalpy of the inlet fluid to the turbine and a decrease in the flow rate of the binary fluid. Consequently, an optimal turbine inlet temperature, which yielded maximum net power output per unit mass flow rate of the geothermal fluid, was obtained for each configuration of ORC. Moreover, for the given operating conditions of the ORCs, one can conclude that the addition of an IHE had minor impact on the thermodynamic performance of the cycle, whereas the regenerative system significantly reduced the cycle performance.

\subsubsection{Sensitivity analysis}

In this section, the variation in the operating temperature for the evaporative and/or condensation processes as well as the temperature of the geothermal resource was assessed to demonstrate the impact on the thermodynamic performance of the proposed binary-cycles. From Fig. 16, the following was observed:

- An increment of $10^{\circ} \mathrm{C}$ in the evaporative temperature resulted in a substantial increase in the rejection exergy destruction back to the exploitation reservoir, at approximately 16-27\%. The exergy destruction of both the evaporative and condensation processes decreased by $20-40 \%$ and $20-25 \%$, respectively. In addition, the ability to convert the total exergy input to useful work output also dropped by approximately $15 \%$.

- A decrease in the condensation temperature by $10^{\circ} \mathrm{C}$ yielded a reduction of roughly $71 \%$ in exergy destruction of the condenser unit for cycles without an IHE and nearly 92\% for those with an IHE. On the other hand, the net power output was increased by $10-15 \%$.

- As the temperature of the geothermal heat was reduced by $10^{\circ} \mathrm{C}$, the net power output was reduced by approximately $18 \%$. In short, a substantial decrease in work output was observed to result from a small decrease in the geothermal resource temperature. 
As illustrated in Fig. 16, more than 51\% of the exergy input from the low-to-moderate grade geothermal heat was lost by the cycle components as discussed by Yari [2]. The addition of an IHE to the binary cycle resulted in a reduction of the exergy destruction in the evaporatorpreheater unit, condenser, and cooling air, by approximately $40-70 \%, 20-30 \%$ and $5-15 \%$, respectively. Adding an $\mathrm{OFOH}$ to the binary cycle, on the other hand, resulted in a remarkable reduction of the exergy destruction in all individual components of the binary cycle, typically $80-90 \%$ for the evaporator-preheater unit, $25-35 \%$ for both the condenser and cooling air, $20-30 \%$ for the turbine, and $10-20 \%$ for the pumping system. The net power output was, however, reduced by $15-25 \%$.

A major drawback with the addition of an IHE and/or OFOH resides in the increase in the rejection exergy destruction: 0-20\% with the addition of an IHE alone, 20-35\% while adding only an $\mathrm{OFOH}$ and up to $40 \%$ for incorporating both IHE and OFOH to the binary cycle. A combined power generation and direct use in process or district heating applications such as a cogeneration system, is thus recommended to improve the geothermal energy utilization while avoiding a susceptible thermal pollution of the environment caused by the geothermal fluid being discarded as waste heat at relatively high temperature [4,28].

\subsection{Performance optimization}

A parametric and thermodynamic optimization was conducted with n-pentane as the organic binary fluid. Optimal operating conditions were determined for maximum power output. An optimal First- and Second-law efficiency was also determined in the given range of the geothermal resource temperature.

In Fig. 17, optimal First- and Second-law efficiencies with respect to the reference temperature $T_{o}$ (Eqs. 10 and 11) were represented. Within the range of the geothermal fluid temperature investigated in this study and based on the geothermal fluid state at the inlet of the primary heat exchanger, the optimal First-law efficiency was obtained in the range of 4$8 \%$ for the non-regenerative ORCs and 2-6\% for the regenerative cycles (Fig. 17a). Likewise, the optimal Second-law efficiency was recorded within $37-47 \%$ and $19-33 \%$ for the nonregenerative and regenerative ORCs, respectively (Fig. 17b).

Minimum overall plant irreversibility and maximum net power output were plotted in Figs. $18 \mathrm{a}$ and $18 \mathrm{~b}$, respectively, per unit mass flow rate of the geothermal fluid. Within the range of the geothermal fluid temperature investigated in this study, the non-regenerative ORCs 
were rated at about 16-49 $\mathrm{kW}$ maximum net power output per unit mass flow rate of the geothermal fluid, as compared to $8-34 \mathrm{~kW}$ for the regenerative cycles. Minimum overall plant irreversibility was observed to increase almost linearly with the heat source temperature, whereas maximum net power output increased exponentially. Hence, a substantial augmentation in the net power output can be achieved with a slight increase in the geothermal resource temperature. Subbiah and Natarajan [13] proposed hybrid cycles operating with solar concentrators, bio-gas heating or fossil-fuel heating as an attempt to increase the power output by increasing the resource fluid temperature.

In Fig. 19, maximum First- and Second-law efficiencies (Eqs. 12 and 13) were plotted based on the energy and exergy input to the ORC, respectively, and at optimum evaporative and condensation operating conditions of the binary-cycles. Within the range of the geothermal fluid temperature investigated in this study, the First-law efficiency was determined in the range of $8-15 \%$ (Fig. 19a), with the regenerative ORCs achieving maximum values. The Second-law efficiency varied from $42 \%$ to $56 \%$ (Fig. 19b). The advantage of adding an IHE and/or an $\mathrm{OFOH}$ to the binary cycle to improve the effectiveness of the conversion of the available geothermal energy into useful work was therefore noticeable with the increase in the heat source temperature. Furthermore, the use of the regenerative ORCs to convert highgrade geothermal heat was justified based on the ability to minimize the exergy destruction (irreversibility) during the heat transfer process.

In Fig. 20, maximum cycle effectiveness is represented. The non-regenerative ORCs were observed to yield a better heat transfer capability of the available energy from the geothermal fluid to the organic binary fluid at $70-74 \%$, as compared to $56-69 \%$ for the regenerative cycles. Here, the high sensitivity of the regenerative cycles to the variations in the geothermal resource temperatures was noticeable, as discussed by Franco and Villani [29].

In terms of the utilization of the available heat source, the regenerative ORCs were preferable for the conversion of low-to-moderate grade geothermal resource within the investigated temperature range, due to the lower ratio of organic binary fluid required per unit mass flow rate of the geothermal fluid (Fig. 21). This could significantly lower the operating and maintenance $(\mathrm{O} \& M)$ cost of the geothermal power plant. 


\section{Conclusions and recommendations}

In this paper, a thermodynamic optimization of geothermal power plants, which operate with a binary-cycle and moderately low temperature and liquid-dominated geothermal resources in the range of $110^{\circ} \mathrm{C}$ to $160^{\circ} \mathrm{C}$ and cooling air at ambient conditions of $25^{\circ} \mathrm{C}$ and $101.3 \mathrm{kPa}$ reference temperature and atmospheric pressure, respectively, was considered. The optimal operating conditions of the binary-cycles were determined for maximum net power output per unit mass flow rate of the geothermal fluid. The authors observed that maximum net power output increased exponentially with the geothermal resource temperature to yield 16-49 kW per unit mass flow rate of the geothermal fluid for the non-regenerative ORCs, as compared to $8-34 \mathrm{~kW}$ for the regenerative cycles. The cycle First-law efficiency was determined in the range of $8-15 \%$ for the investigated geothermal binary power cycles. Maximum Second-law efficiency of approximately $56 \%$ was achieved by the ORC with an IHE. With the increase in the heat source temperature, the addition of an IHE and/or an OFOH to the binary cycle has proven to significantly improve the effectiveness of the conversion of the available geothermal energy into useful work, as well as the cycle First-law efficiency. The regenerative cycles were preferred for high-grade geothermal heat due to their ability to minimize the exergy destruction (irreversibility) during the heat transfer process. A combined power generation and direct use in process or district heating applications such as a cogeneration system, is thus recommended to improve the geothermal energy utilization while avoiding a susceptible thermal pollution of the environment caused by the geothermal fluid being discarded as waste heat at relatively high temperature [4,28]. In addition, a performance analysis of pure organic fluids such as R123, R152a, isobutane and n-pentane, with boiling points in the range of $-24^{\circ} \mathrm{C}$ to $36^{\circ} \mathrm{C}$, was conducted under saturation temperature and subcritical pressure operating conditions of the turbine. Organic fluids with higher boiling point temperature, such as n-pentane, were recommended for non-regenerative cycles. The regenerative ORCs, however, require organic fluids with lower vapour specific heat capacity (i.e. isobutane) for an optimal operation of the binary-cycle.

\section{Acknowledgements}

The authors acknowledge with gratitude the support from the University of Pretoria. The funding obtained from Hitachi Power Africa and the National Research Foundation (NRFDST) is likewise appreciated. 


\section{References}

[1] Kanoglu, M 2002, 'Exergy analysis of a dual-level binary geothermal power plant', Geothermics, vol. 31, no. 1, pp. 709-724.

[2] Yari, M 2010, 'Exergetic analysis of various types of geothermal power plants', Renewable Energy, vol. 35, no. 1, pp. 112-121.

[3] Bodvardson, G \& Eggers, DE 1972, 'The exergy of thermal water', Geothermics, vol. 1, no. 3, pp. 93-5.

[4] Kanoglu, M \& Bolatturk, A 2008, 'Performance and parametric investigation of a binary geothermal power plant by exergy', Renewable Energy, vol. 33, no. 1, pp. 2366-74.

[5] Franco, A 2011, 'Power production from a moderate temperature geothermal resource with regenerative Organic Rankine Cycles', Energy for Sustainable Development, vol. 15, pp. 411-419.

[6] DiPippo, R 2004, 'Second Law assessment of binary plants generating power from lowtemperature geothermal fluids, Geothermics, vol. 33, no.1, pp. 565-86.

[7] Madhawa, HD, Mihajlo, G, Worek, WM \& Yasuyuki, I 2007, 'Optimum design criteria for an organic Rankine cycle using low temperature geothermal heat sources', Energy, vol. 32, no. 1, pp. 1698-706.

[8] Gu, Z \& Sato, H 2001, 'Optimization of cyclic parameters of a supercritical cycle for geothermal power generation', Energy Conversion and Management, vol. 42, no. 1, pp. 1409-1416.

[9] DiPippo, R 2008, Geothermal power plants principles, applications, case studies and environmental impact, Butterworth-Heinemann, London.

[10] Desai, N \& Bandyopadhyay, S 2009, 'Process integration of organic Rankine cycle', Energy, vol. 34, no. 1, pp. 1674-86.

[11] Gnutek, Z \& Bryszewska-Mazurek, A 2001, 'The thermodynamic analysis of multicycle ORC engine', Energy, vol. 26, no. 1, pp. 1075-1082.

[12] Borsukiewicz-Gozdur, A \& Nowak, W 2007, 'Maximising the working fluid flow as a way of increasing power output of geothermal power plant', Applied Thermal Engineering, vol. 27, pp. 2074-8.

[13] Subbiah, S \& Natarajan, R 1988, 'Thermodynamic analysis of binary-fluid rankine cycles for geothermal power plants', Energy Conversion and Management, vol. 28, no. 1, pp. 47-52.

[14] Saleh, B, Koglbauer, G, Wendland M \& Fischer, J 2007, 'Working fluids for lowtemperature organic Rankine cycles', Energy, vol. 32, no. 7, pp. 1210-1221. 
[15] Klein, SA 2012, 'Engineering Equation Solver EES Academic Commercial V7.933', McGraw Hill. See also https://www.fchart.com.

[16] Bejan, A 1993, Heat transfer, Wiley, New York.

[17] Yekoladio, PJ, Bello-Ochende, T \& Meyer JP 2013, 'Design and optimization of the downhole coaxial heat exchanger for Enhanced Geothermal System (EGS)', Journal of Renewable Energy, vol. 55, pp. 128-137.

[18] Demuth, OJ \& Kochan, RJ 1981, Analyses of mixed hydrocarbon binary thermodynamic cycles for moderate temperature geothermal resources using regeneration techniques, INEL Rep. EGG-GTH-05710, Idaho Falls, ID.

[19] Aljundi, IH 2011, 'Effect of dry hydrocarbons and critical point temperature on the efficiencies of organic Rankine cycle', Renewable Energy, vol. 36, no.1, pp 1196-1202.

[20] Mago, PJ, Chamra, LM, Srinivasan, K \& Somayaji, C, 2008, 'An examination of regenerative organic Rankine cycles using dry fluids', Applied Thermal Engineering, vol. 28, no. 1, pp. 998-1007.

[21] Chen, H, Goswami, DY \& Stefanakos, EK 2010, 'A review of thermodynamic cycles and working fluids for the conversion of low-grade heat', Renewable and sustainable energy reviews, vol. 14, no. 1, pp. 3059-3067.

[22] Hepbasli, A 2008, 'A key review on exergetic analysis and assessment of renewable energy resources for a sustainable future', Renewable and Sustainable Energy Reviews, vol. 12, pp. 593-661.

[23] Kaplan, U 2007, Advanced organic Rankine cycles in binary geothermal power plants, World Energy Council, Ormat Technologies, inc.

[24] Lakew, AA \& Bolland, O 2010, 'Working fluids for low-temperature heat source', Applied Thermal Engineering, vol. 30, no. 1, pp. 1262-1268.

[25] Maizza, V \& Maizza, A 1996, 'Working fluids in non-steady flows for waste energy recovery systems', Applied Thermal Engineering, vol. 16, no. 1, pp. 579-90.

[26] Tchanche, BF, Lambrinos, Gr, Frangoudakis, A \& Papadakis G 2011, 'Low-grade heat conversion into power using organic Rankine cycles- A review of various applications', Renewable and Sustainable Energy Review, vol. 15, no.1, pp. 3963-3979.

[27] DiPippo, R 1999, 'Small geothermal power plants: Design, performance and economics', Geothermal Resources Council BULLETIN, pp. 1-8.

[28] Guo, T, Wang, HX \& Zhang, SJ 2011, 'Fluids and parameters optimization for a novel cogeneration system driven by low-temperature geothermal sources', Energy, vol. 36, no. 1, pp. 2639-2649. 
[29] Franco, A \& Villani, M 2009, 'Optimum design of binary cycle power plants for waterdominated, medium-temperature geothermal fields', Geothermics, vol. 38, no.1, pp. 379-391. 


\section{Tables}

Table 1: Thermo-physical and environmental properties of the investigated pure organic fluids [13,21]

\begin{tabular}{|c|c|c|c|c|}
\hline Working fluid & R123 & R152a & R600a & R601 \\
\hline Name & $\begin{array}{l}\text { 2,2-Dichloro-1,1,1- } \\
\text { trifluoroethane }\end{array}$ & $\begin{array}{c}1,1- \\
\text { Difluoroethane }\end{array}$ & Isobutane & n-Pentane \\
\hline Chemical formula & $\mathrm{CHCl}_{2} \mathrm{C}-\mathrm{F}_{3}$ & $\mathrm{CH}_{3} \mathrm{CH}-\mathrm{F}_{2}$ & $\mathrm{C}_{4} \mathrm{H}_{10}$ & $C_{5} H_{12}$ \\
\hline Type & $\mathrm{HCFC}$ & $\mathrm{HFC}$ & $\mathrm{HC}$ & $\mathrm{HC}$ \\
\hline Organic type & Isentropic & Wet & Dry & Dry \\
\hline \multicolumn{5}{|c|}{ Thermo-physical properties } \\
\hline Molecular weight & 152.93 & 66.05 & 58.12 & 72.15 \\
\hline$T_{b p} @ 1 \mathrm{~atm}\left[{ }^{\circ} C\right]$ & 27.82 & -24.02 & -11.67 & 36.0 \\
\hline$T_{c r}\left[{ }^{o} C\right]$ & 183.68 & 113.26 & 134.67 & 196.55 \\
\hline $\boldsymbol{P}_{c r}[\mathbf{M P a}]$ & 3.662 & 4.517 & 3.62 & 3.37 \\
\hline$C p_{v}[\mathrm{~J} / \boldsymbol{k g} \cdot \mathbf{K}]$ & 738.51 & 1456.02 & 181.42 & 1824.12 \\
\hline$L[\mathbf{k J} / \mathbf{k g}]$ & 161.82 & 249.67 & 303.44 & 349.00 \\
\hline \multicolumn{5}{|c|}{ Environmental properties } \\
\hline$A L T$ [year] & 1.3 & 1.4 & 0.02 & $<<1$ \\
\hline$O D P[-]$ & 0.02 & 0.000 & 0.000 & 0.000 \\
\hline$G W P[100$ years $]$ & 77 & 120 & $\sim 20$ & 11 \\
\hline
\end{tabular}


Table 2: Operating parameters used in the validation of results

\begin{tabular}{lcccccccccc}
\hline Parameters & $P_{o}$ & $P_{\text {ext }}$ & $T_{o}$ & $T_{C}$ & $T_{E}$ & $T_{g e o}$ & $\Delta T_{p p}$ & $\eta_{P}$ & $\eta_{t}$ & $\varepsilon_{I H E}$ \\
\hline Unit & $\mathbf{k P a}$ & $\mathbf{k P a}$ & ${ }^{\mathbf{0}} \mathbf{C}$ & ${ }^{\mathbf{0}} \mathbf{C}$ & ${ }^{\mathbf{0}} \mathbf{C}$ & ${ }^{\mathbf{0}} \mathbf{C}$ & ${ }^{\mathbf{0}} \mathbf{C}$ & $\mathbf{\%}$ & $\mathbf{\%}$ & $\mathbf{\%}$ \\
\hline Value & 101.3 & $494^{*}$ & 25 & 40 & 120 & 180 & 10 & 90 & 80 & 80 \\
& & $581^{* *}$ & & & & & & & & \\
\hline
\end{tabular}

* For the regenerative ORC

** For the regenerative ORC with an IHE 
Table 3: Validation of the numerical model with a previously published data [2]

\begin{tabular}{|c|c|c|c|c|c|c|c|c|}
\hline \multirow{2}{*}{$\begin{array}{l}\text { Performance } \\
\text { parameters }\end{array}$} & \multicolumn{2}{|c|}{ Basic ORC } & \multicolumn{2}{|c|}{ ORC with IHE } & \multicolumn{2}{|c|}{ Regenerative ORC } & \multicolumn{2}{|c|}{$\begin{array}{c}\text { Regenerative ORC } \\
\text { with IHE }\end{array}$} \\
\hline & Present work & [2] & Present work & [2] & Present work & [2] & Present work & [2] \\
\hline$\dot{W}_{n e t}[\mathrm{~kJ} / \mathrm{kg}]$ & 50.29 & 50.38 & 50.29 & 50.38 & 44.13 & 43.61 & 43.88 & 44.02 \\
\hline$\dot{E} x_{\text {dest }}[\mathrm{kJ} / \mathrm{kg}]$ & 79.67 & 80.25 & 79.67 & 80.25 & 85.84 & 85.98 & 86.09 & 86.59 \\
\hline$\eta_{I}[\%]$ & 7.37 & 7.65 & 7.37 & 7.65 & 6.466 & 6.623 & 6.43 & 6.686 \\
\hline$\eta_{I, 2}[\%]$ & 13.06 & 13.28 & 13.97 & 14.2 & 14.49 & 14.52 & 15.08 & 15.35 \\
\hline$\eta_{I I}[\%]$ & 37.84 & 38.76 & 37.84 & 38.76 & 33.2 & 33.56 & 33.01 & 33.87 \\
\hline$\eta_{I I, 2}[\%]$ & 48.56 & 49.06 & 50.92 & 51.4 & 50.64 & 50.39 & 52.20 & 52.73 \\
\hline$\varepsilon[\%]$ & 63.28 & 64.33 & 64.75 & 65.82 & 62.5 & 62.67 & 64.25 & 65.41 \\
\hline
\end{tabular}




\section{Figures}
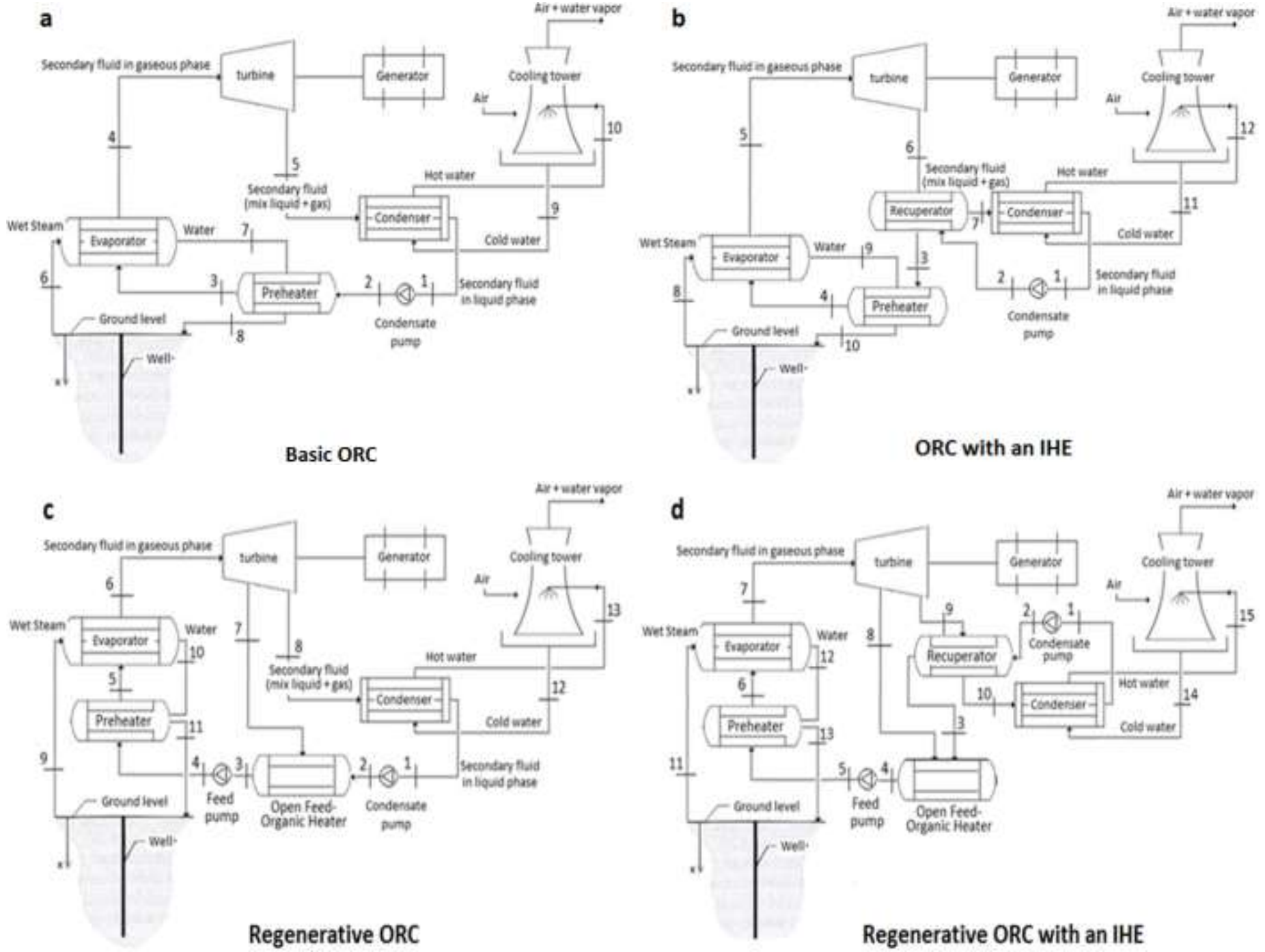

Figure 1: Schematic diagrams of the proposed binary-cycles 

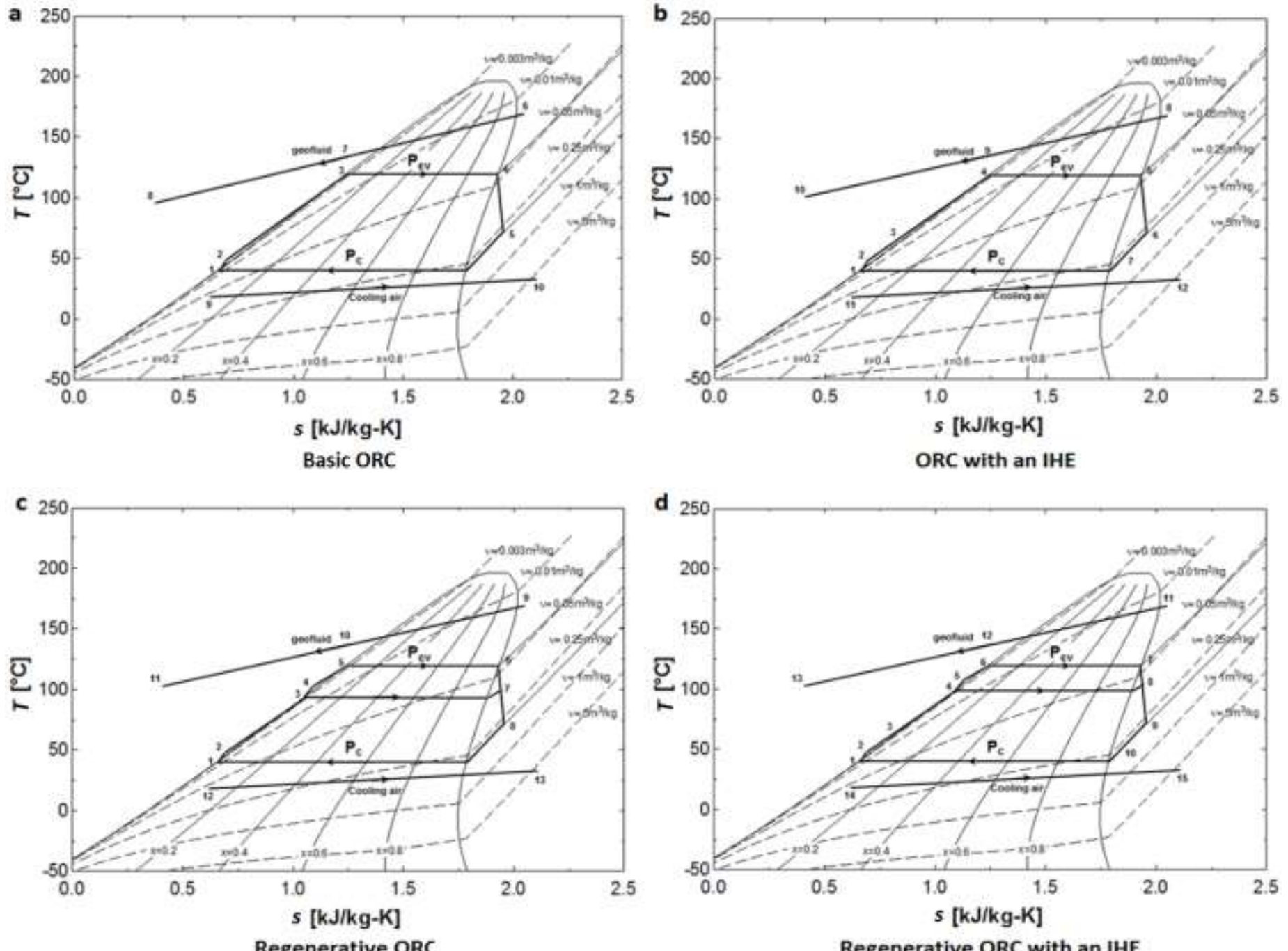

Figure 2: $T$-s diagrams of the proposed binary-cycles 

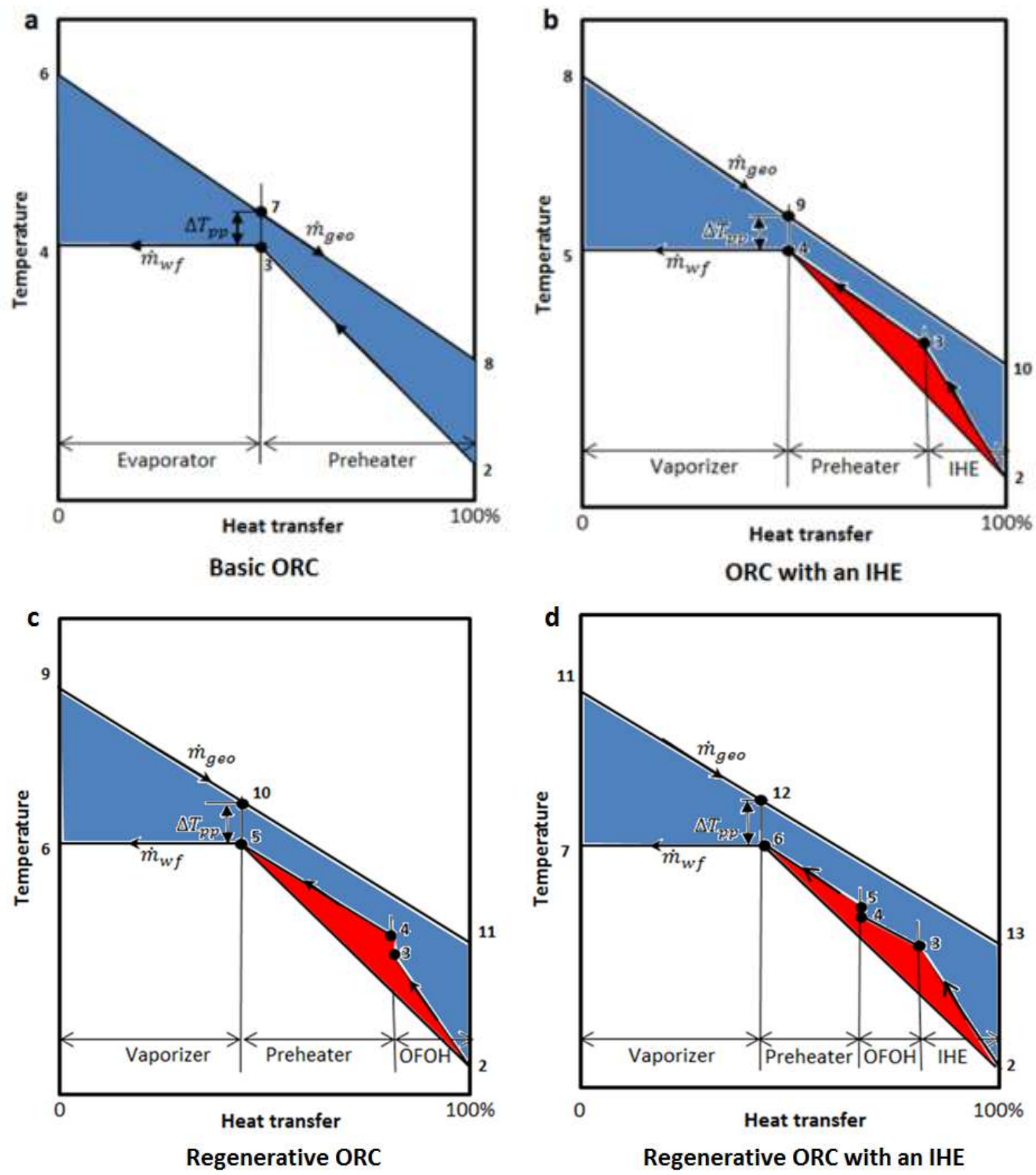

Figure 3: $T-\dot{Q}$ diagrams of the heat exchange process in the evaporator-preheater unit 


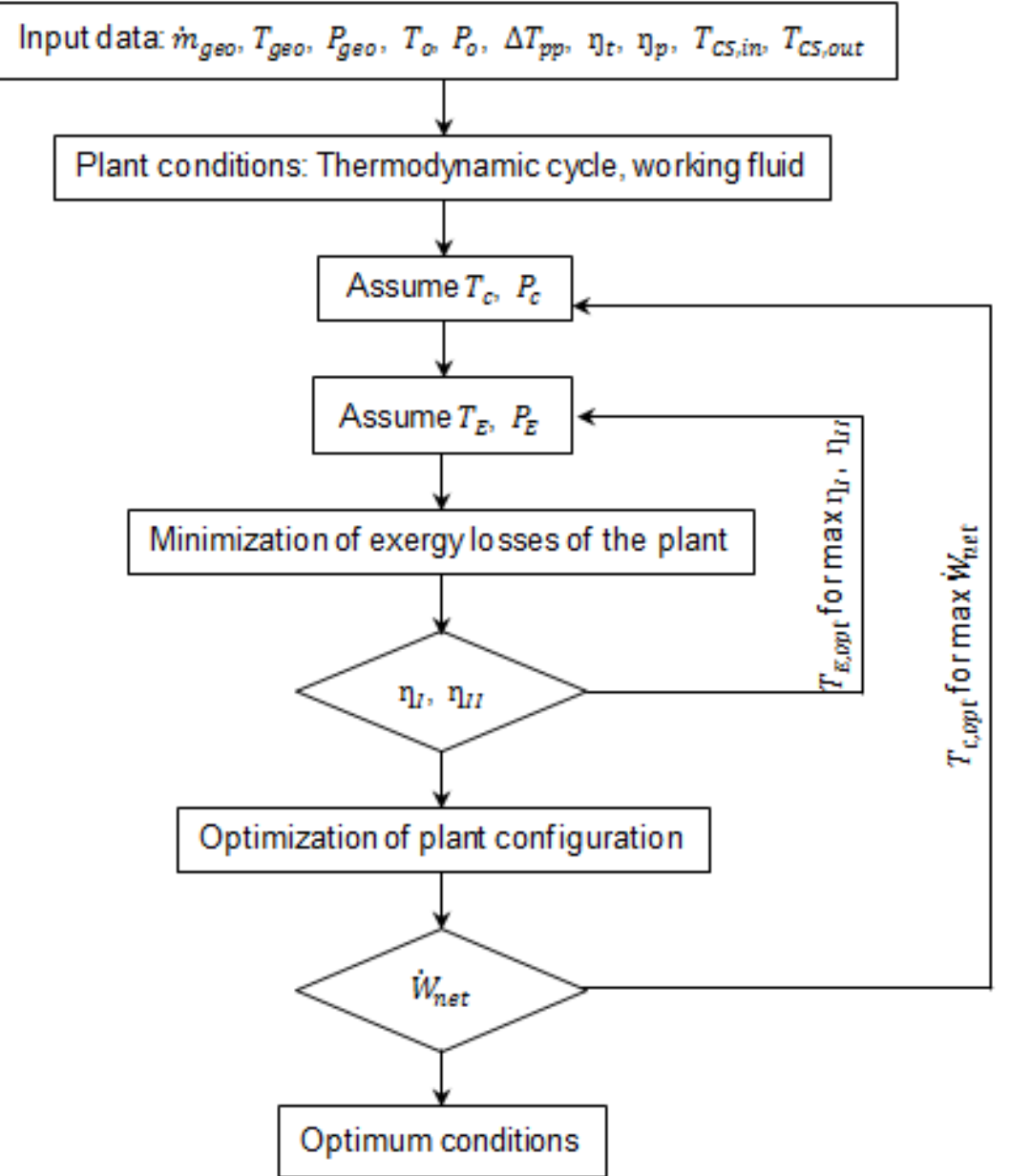

Figure 4: Flow chart of the simulation procedure 
a
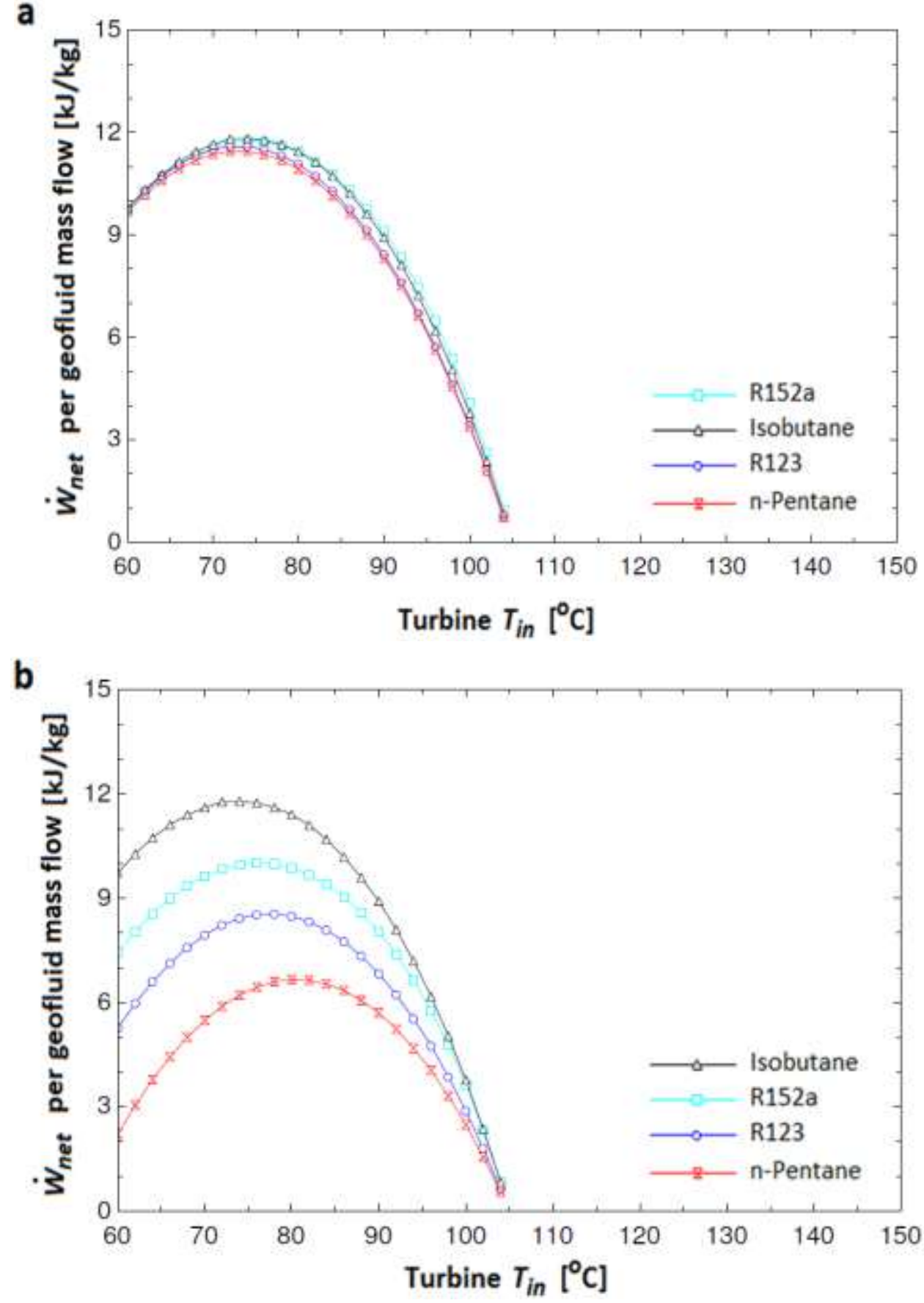

Figure 5: Net power output per geofluid mass flow for geothermal resource temperature of $110^{\circ} \mathrm{C}$ (a) Basic ORC and (b) Regenerative ORC 

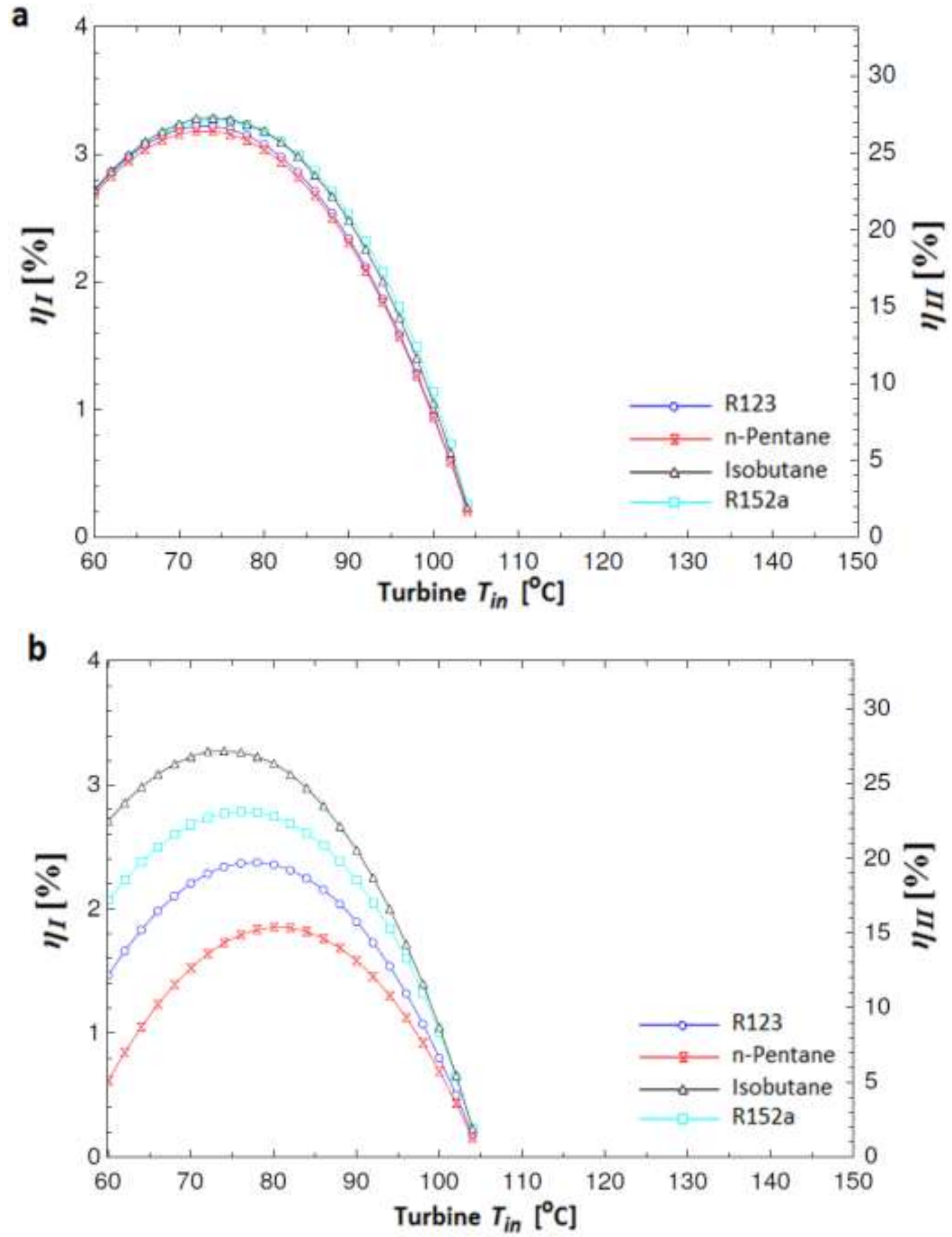

Figure 6: First- and Second-law efficiency with respect to $T_{o}$ for geothermal resource temperature of $110^{\circ} \mathrm{C}$ (a) Basic ORC and (b) Regenerative ORC 

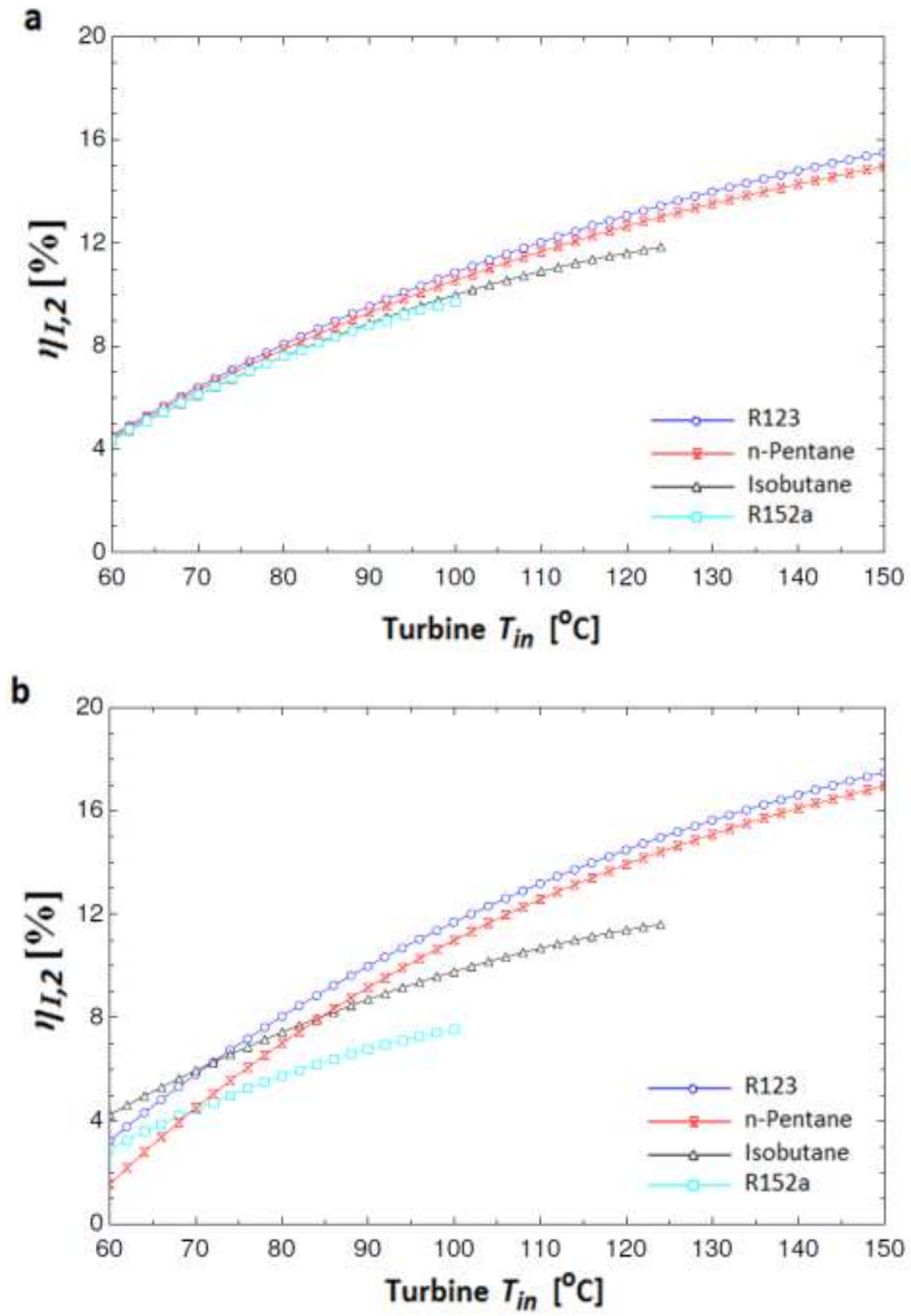

Figure 7: First-law efficiency based on energy input to the ORC (a) Basic ORC and (b) Regenerative ORC 

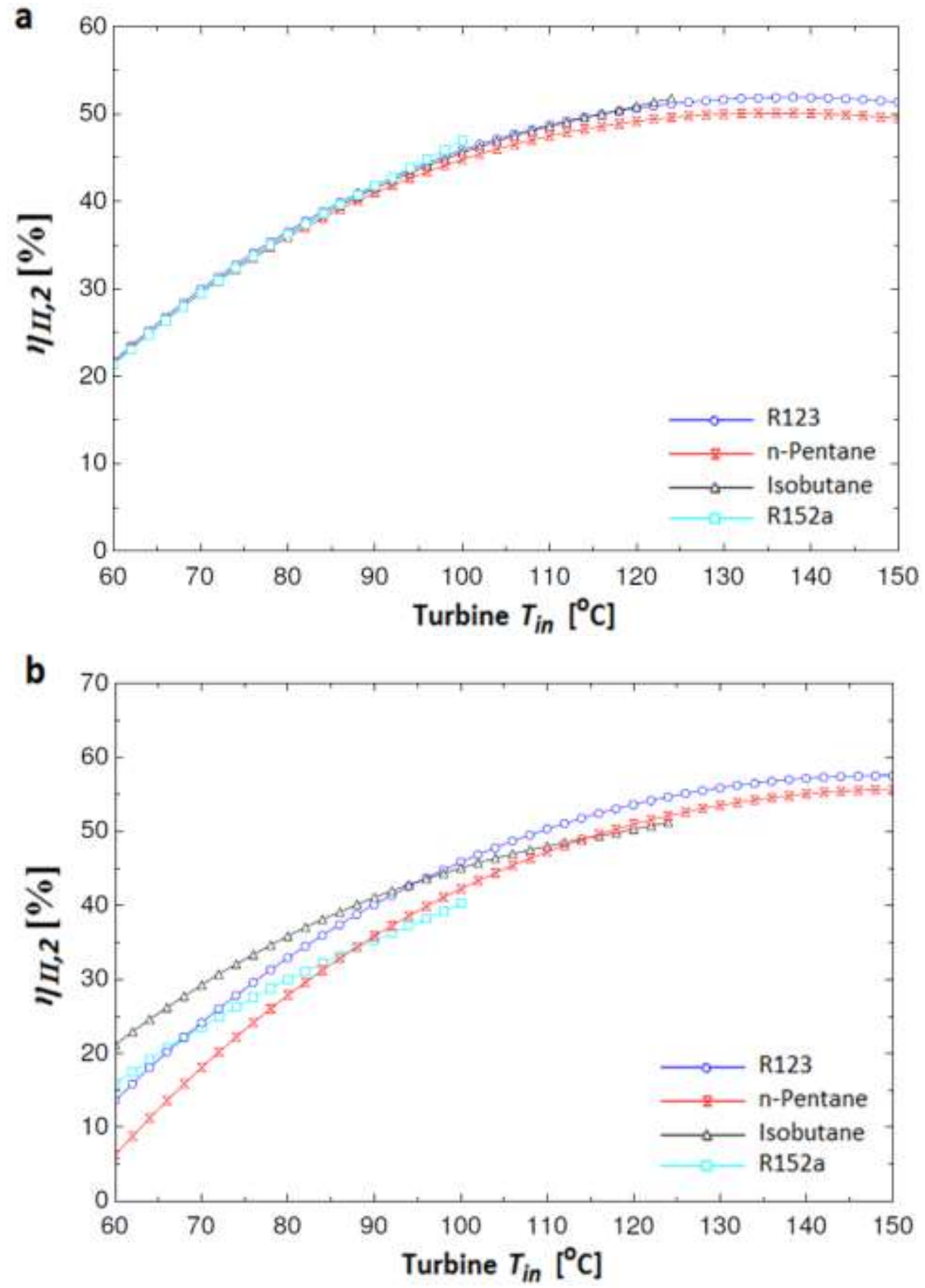

Figure 8: Second-law efficiency based on exergy input to the ORC (a) Basic ORC and (b) Regenerative ORC 

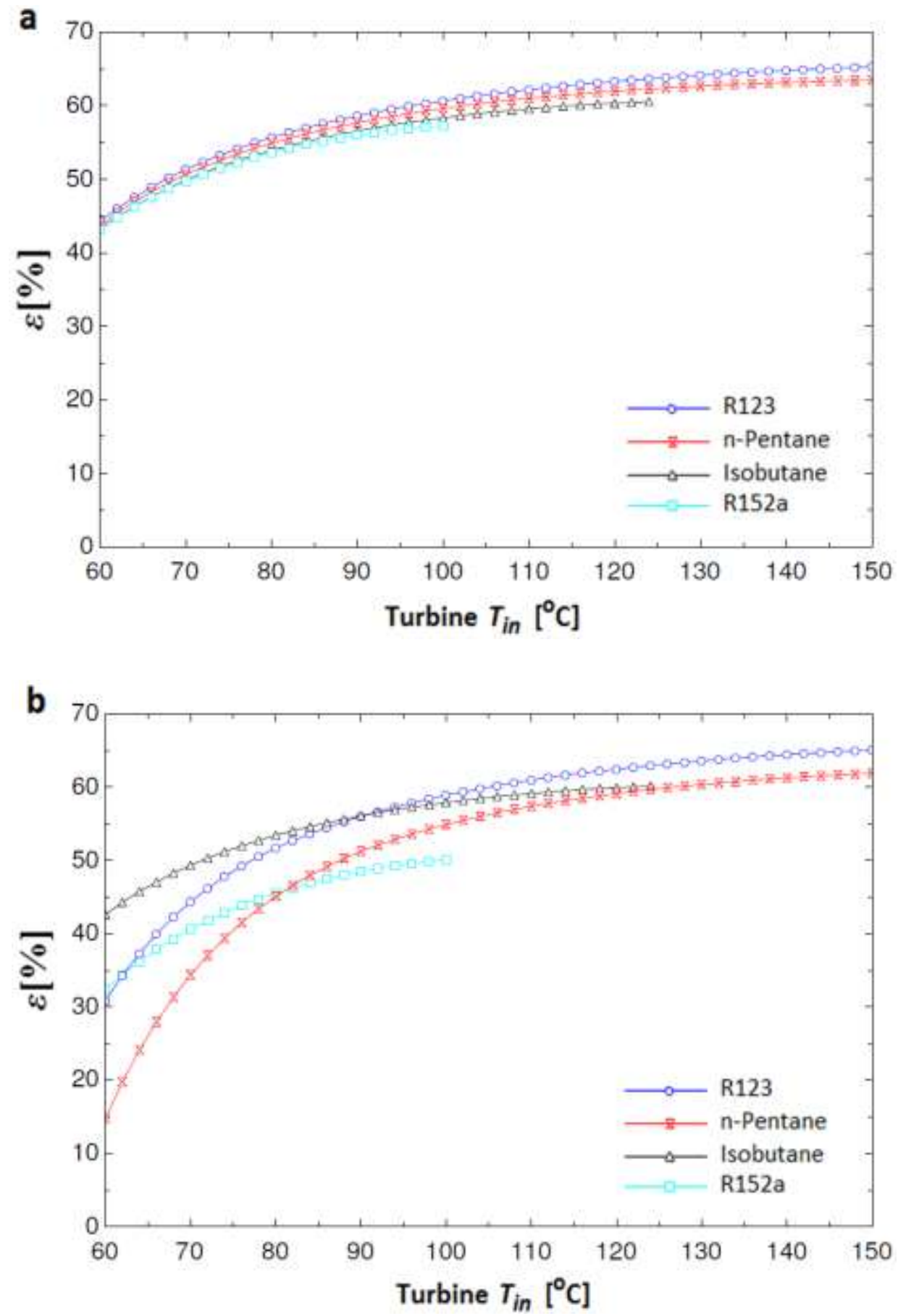

Figure 9: Cycle effectiveness for (a) Basic ORC and (b) Regenerative ORC 

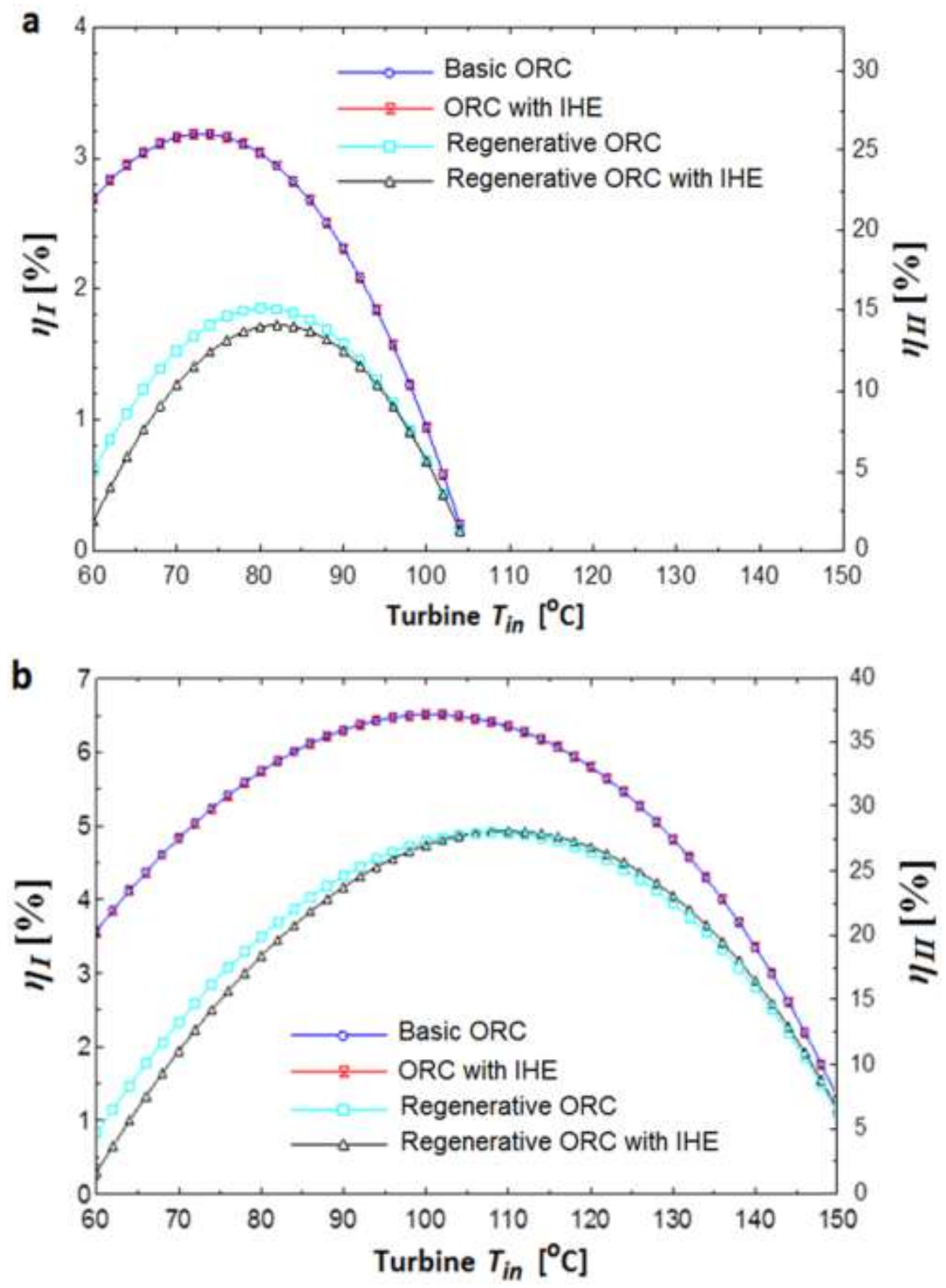

Figure 10: First- and Second-law efficiency with respect to $T_{o}$ for geothermal resource temperature of $(a) 110^{\circ} \mathrm{C}$ and (b) $160^{\circ} \mathrm{C}$, and with $\mathrm{n}$-Pentane as organic binary fluid 

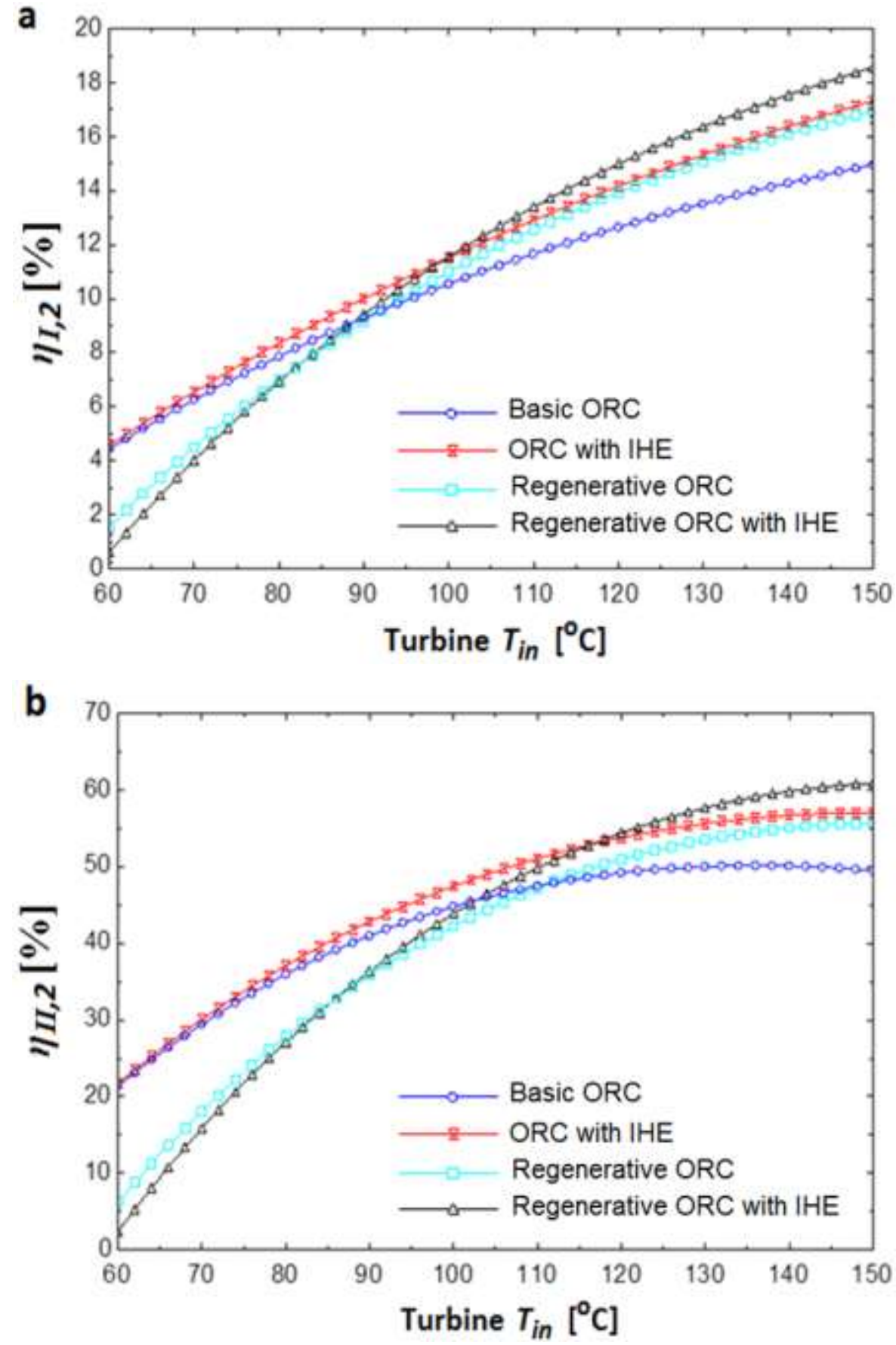

Figure 11: (a) First- and (b) Second-law efficiency based on energy and exergy input to the ORC, and with n-Pentane as organic binary fluid 


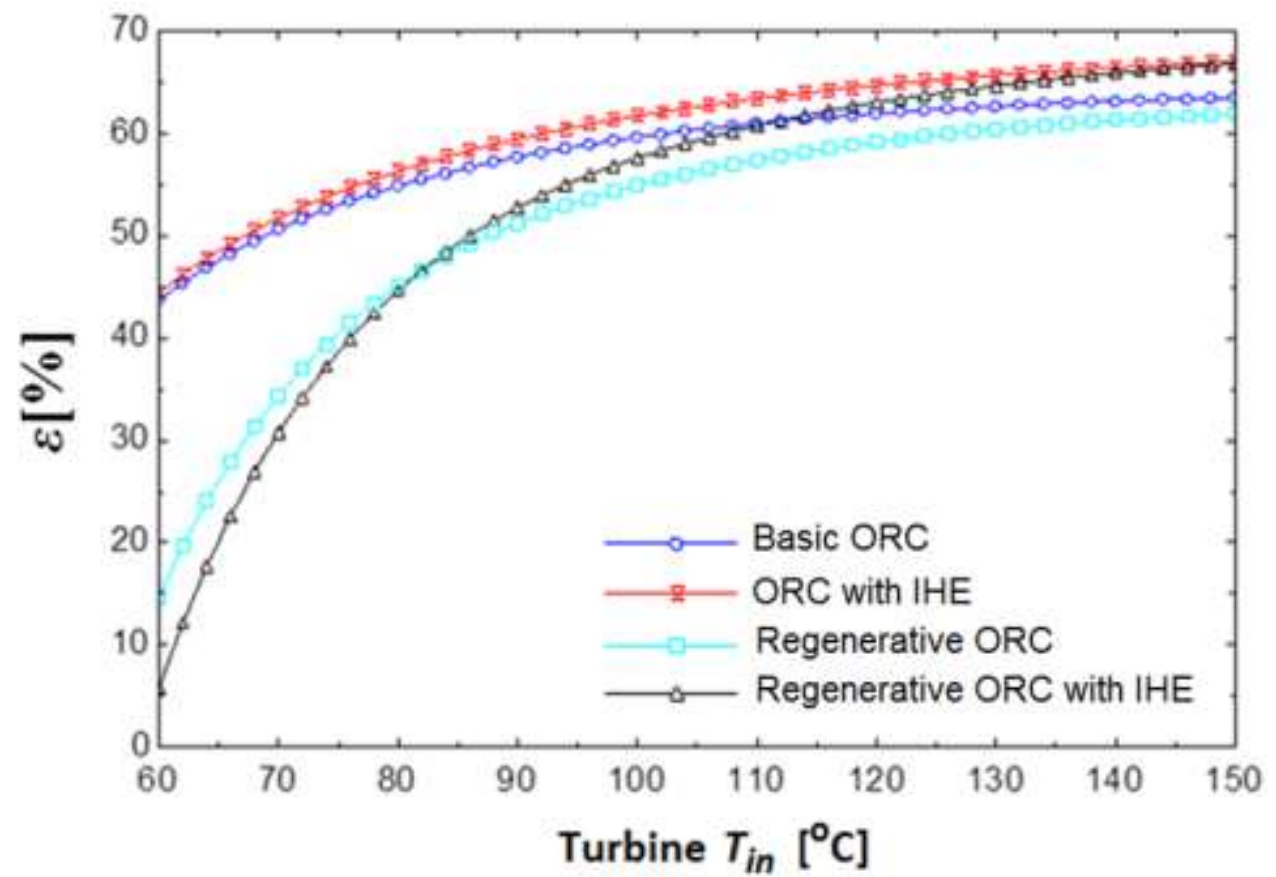

Figure 12: Cycle effectiveness, with n-Pentane as organic binary fluid 

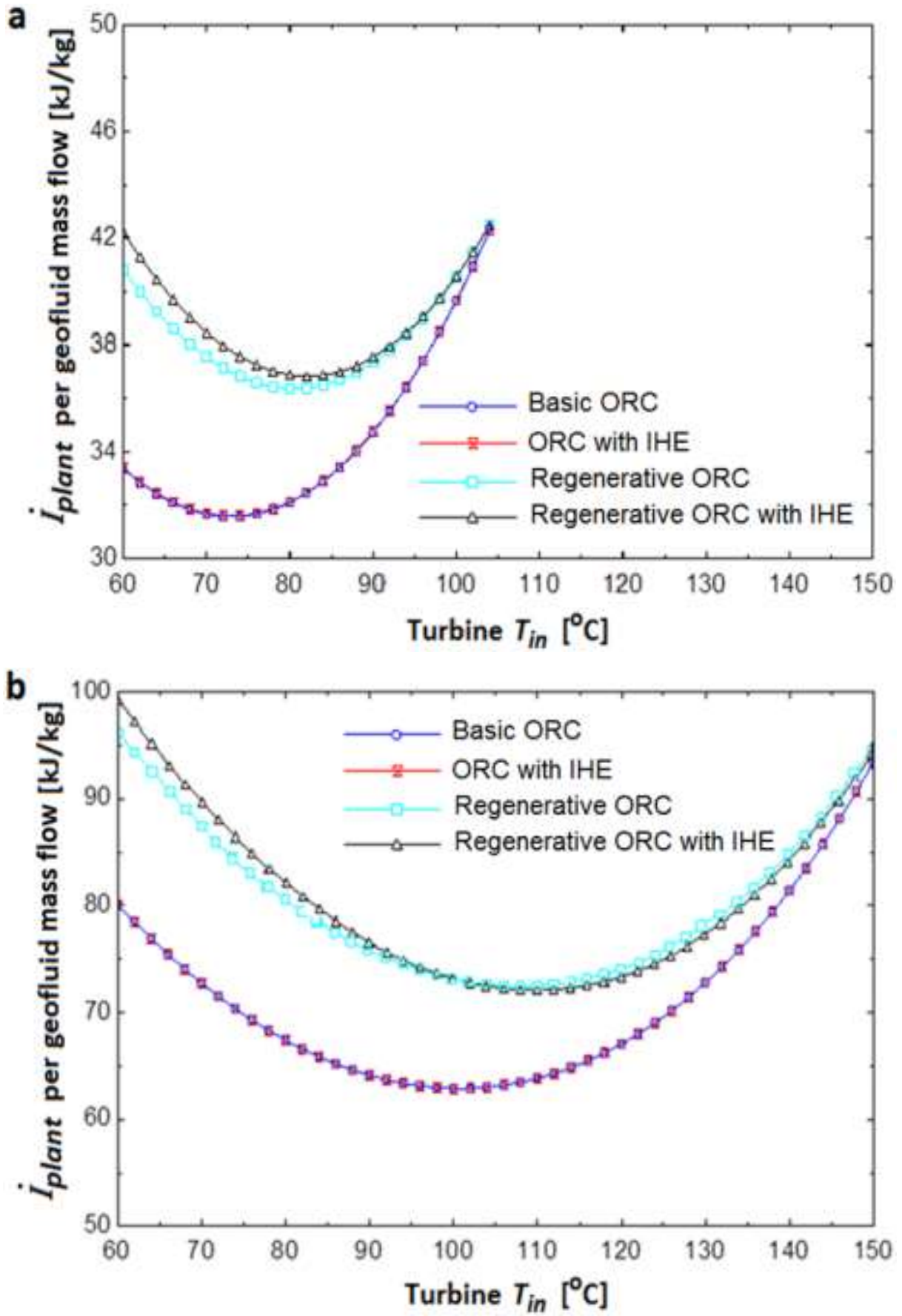

Figure 13: Overall plant irreversibility for geothermal resource temperature of (a) $110^{\circ} \mathrm{C}$ and $(b) 160^{\circ} \mathrm{C}$, and with $\mathrm{n}$-Pentane as organic binary fluid 

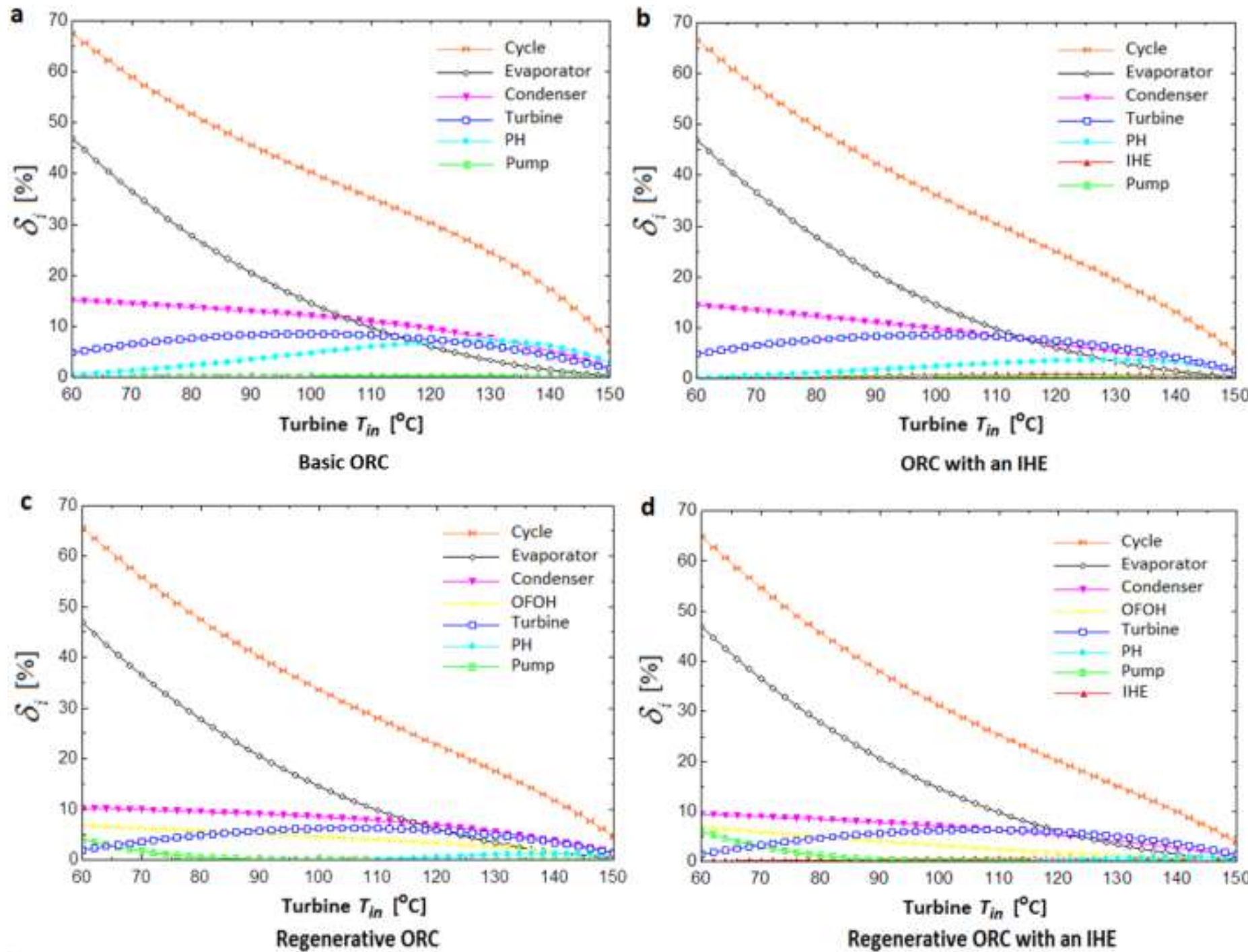

Figure 14: Fuel depletion ratio for geothermal resource temperature of $160^{\circ} \mathrm{C}$, and with n-Pentane as organic binary fluid 

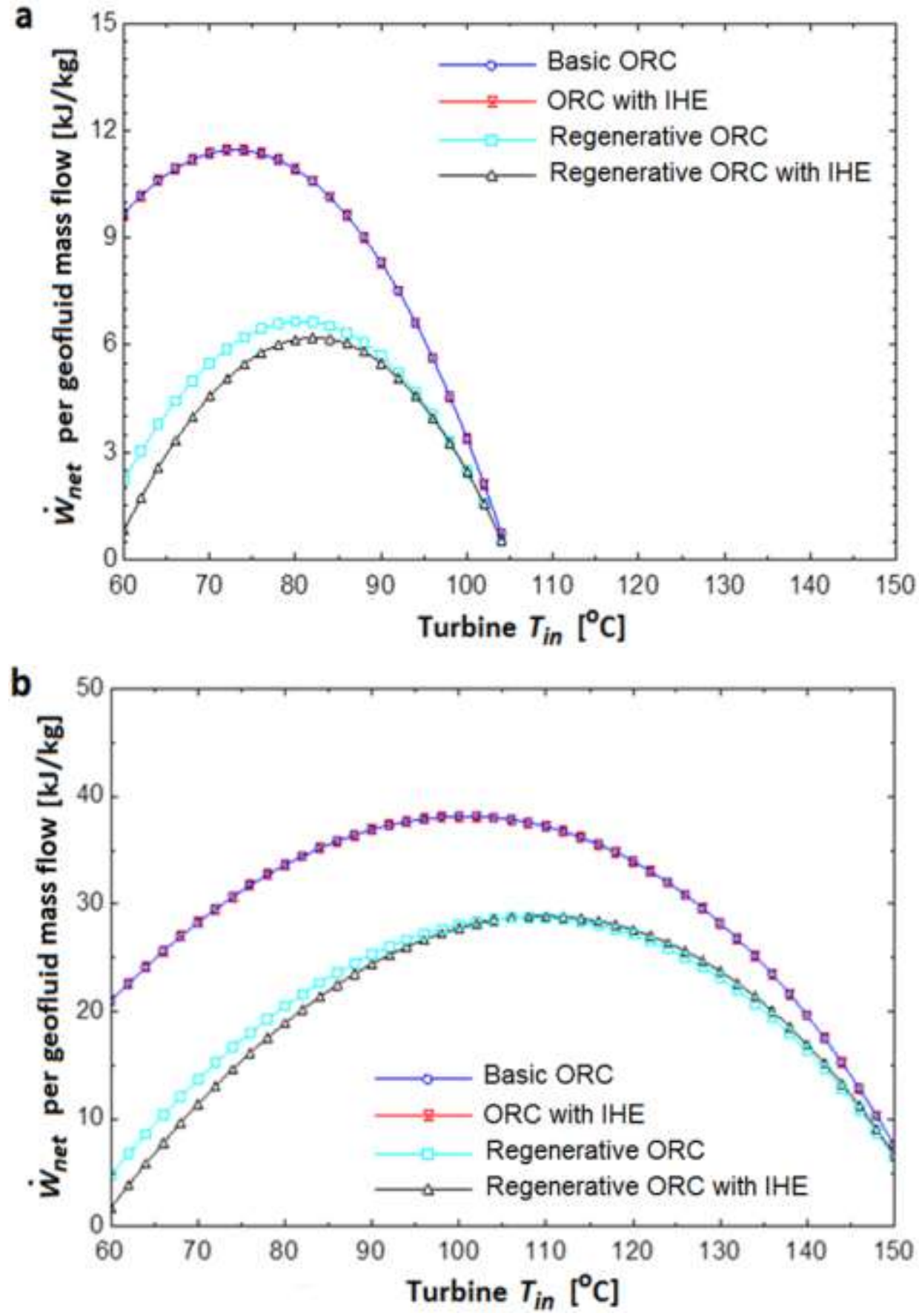

Figure 15: Net power output per geofluid mass flow for geothermal resource temperature of (a) $110^{\circ} \mathrm{C}$ and (b) $160^{\circ} \mathrm{C}$, and with n-Pentane as organic binary fluid 


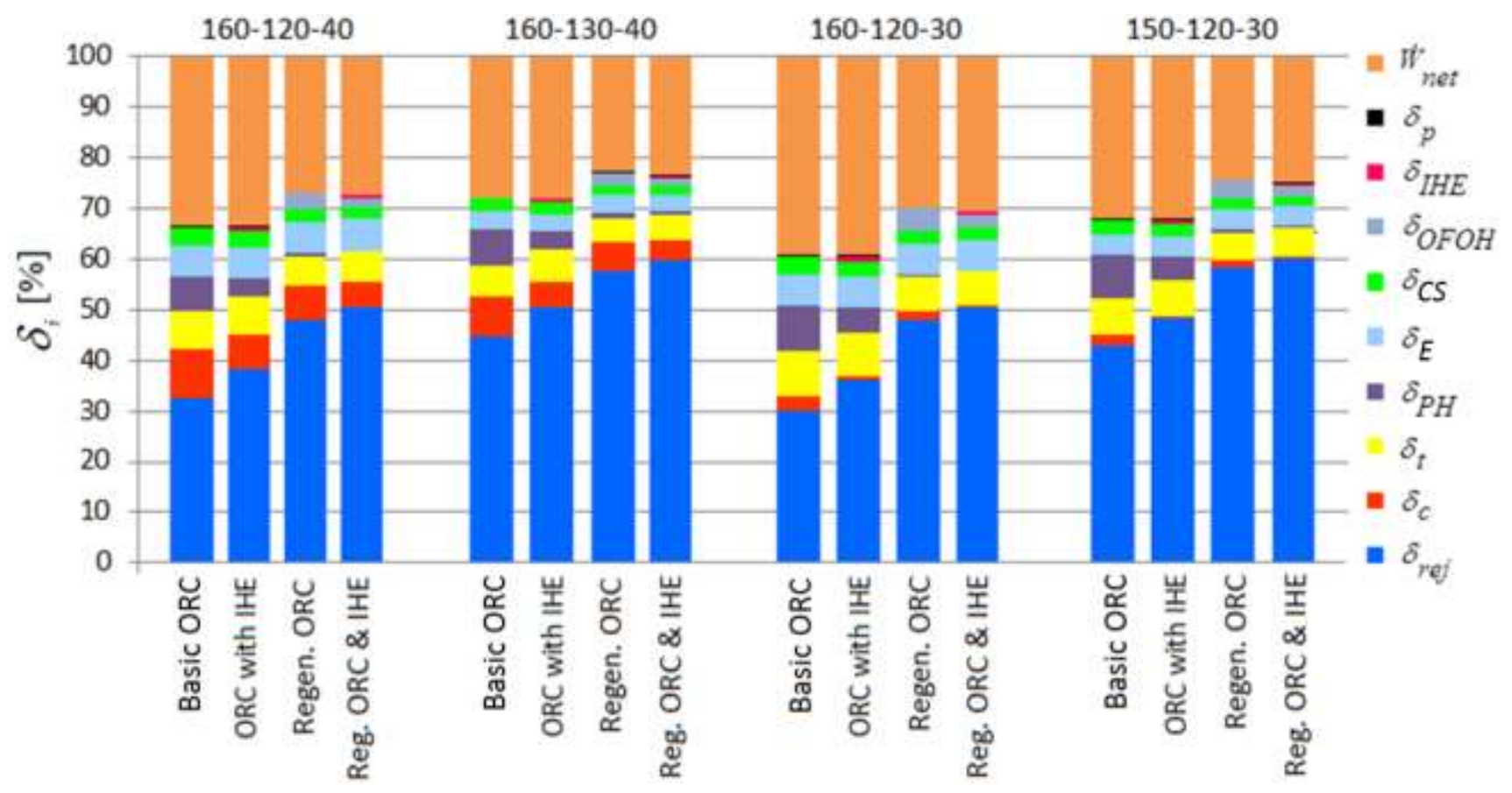

Figure 16: Variation of Fuel depletion ratio with $T_{g e o}, T_{E}$ and $T_{c}$ (given in ${ }^{\circ} \mathrm{C}$ ), and with n-Pentane as organic binary fluid 

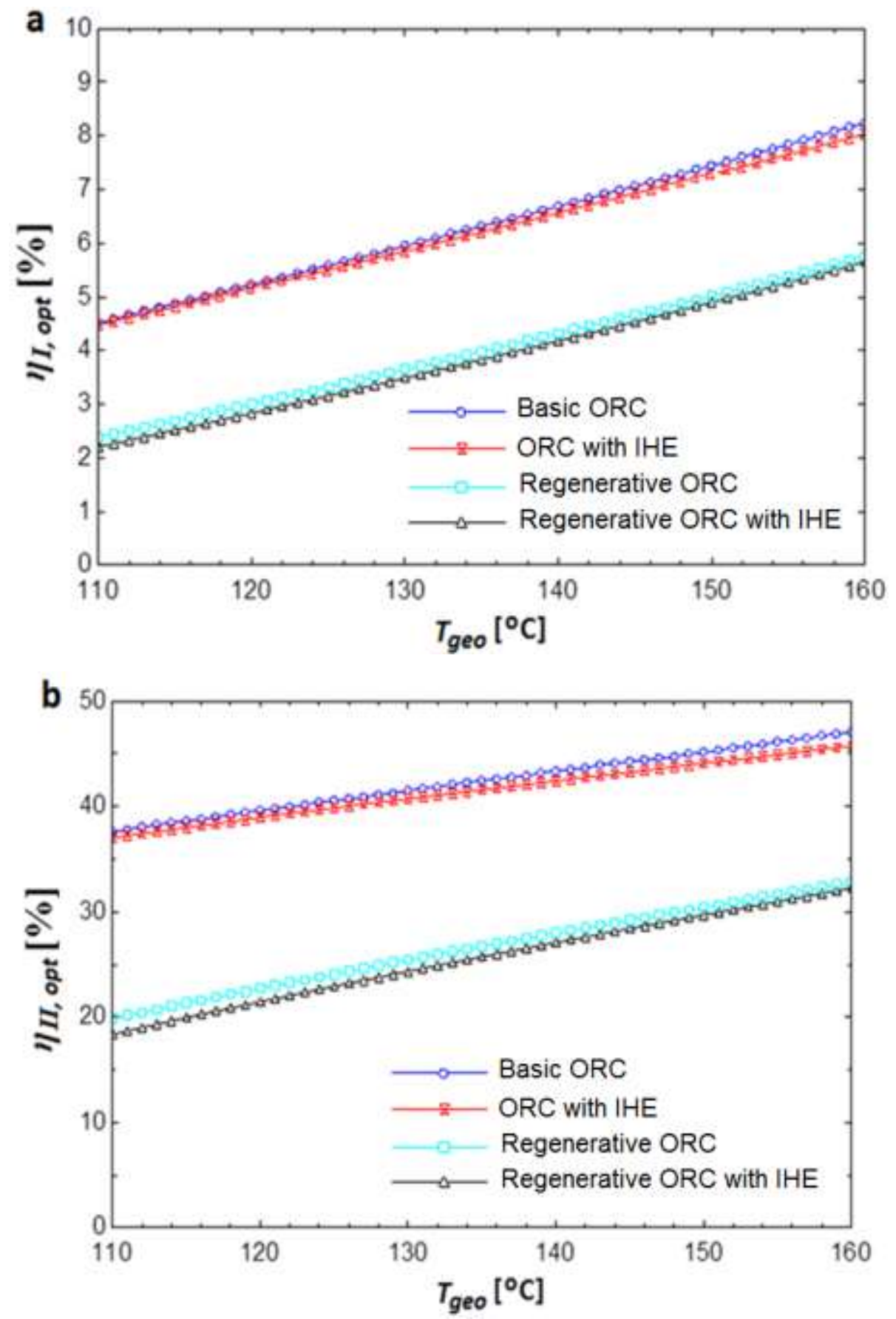

Figure 17: Optimal (a) First- and (b) Second-law efficiency with respect to $T_{o}$, and with n-Pentane as organic binary fluid 

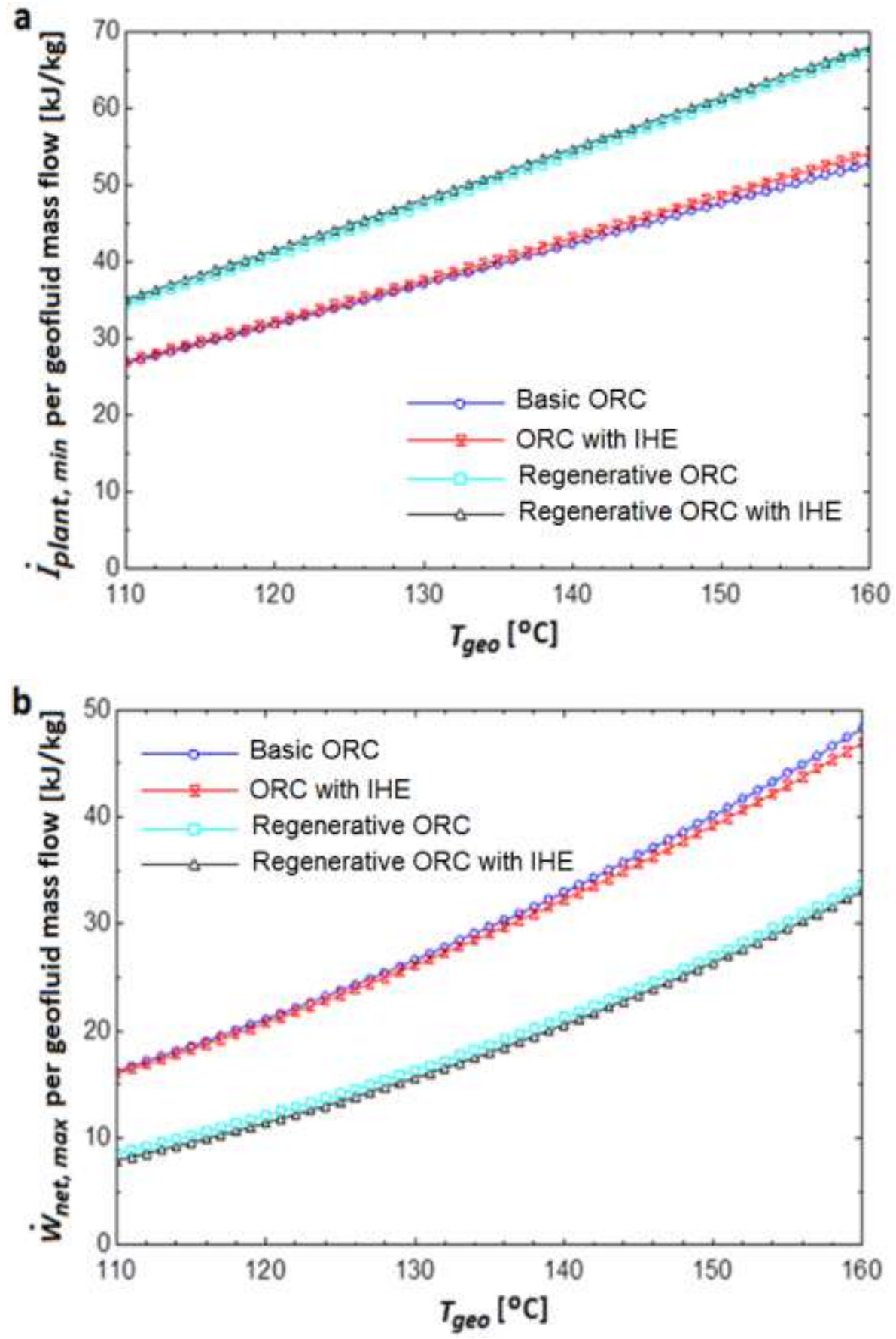

Figure 18: (a) Minimum overall plant irreversibility and (b) maximum net power output per geofluid mass flow, and with n-Pentane as organic binary fluid 

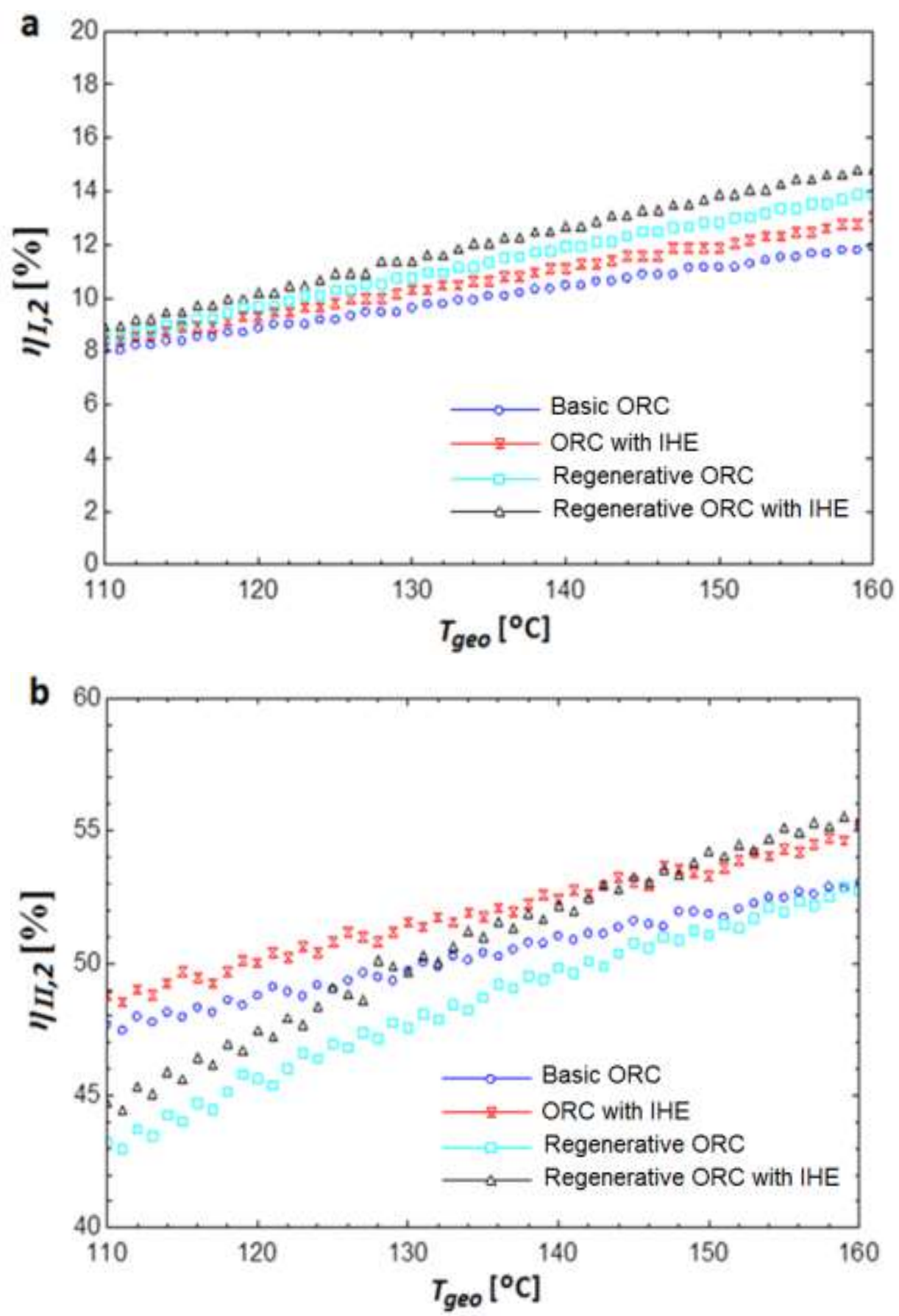

Figure 19: (a) First- and (b) Second-law efficiency based on energy and exergy input to the ORC at the optimum operating conditions, and with n-Pentane as organic binary fluid 


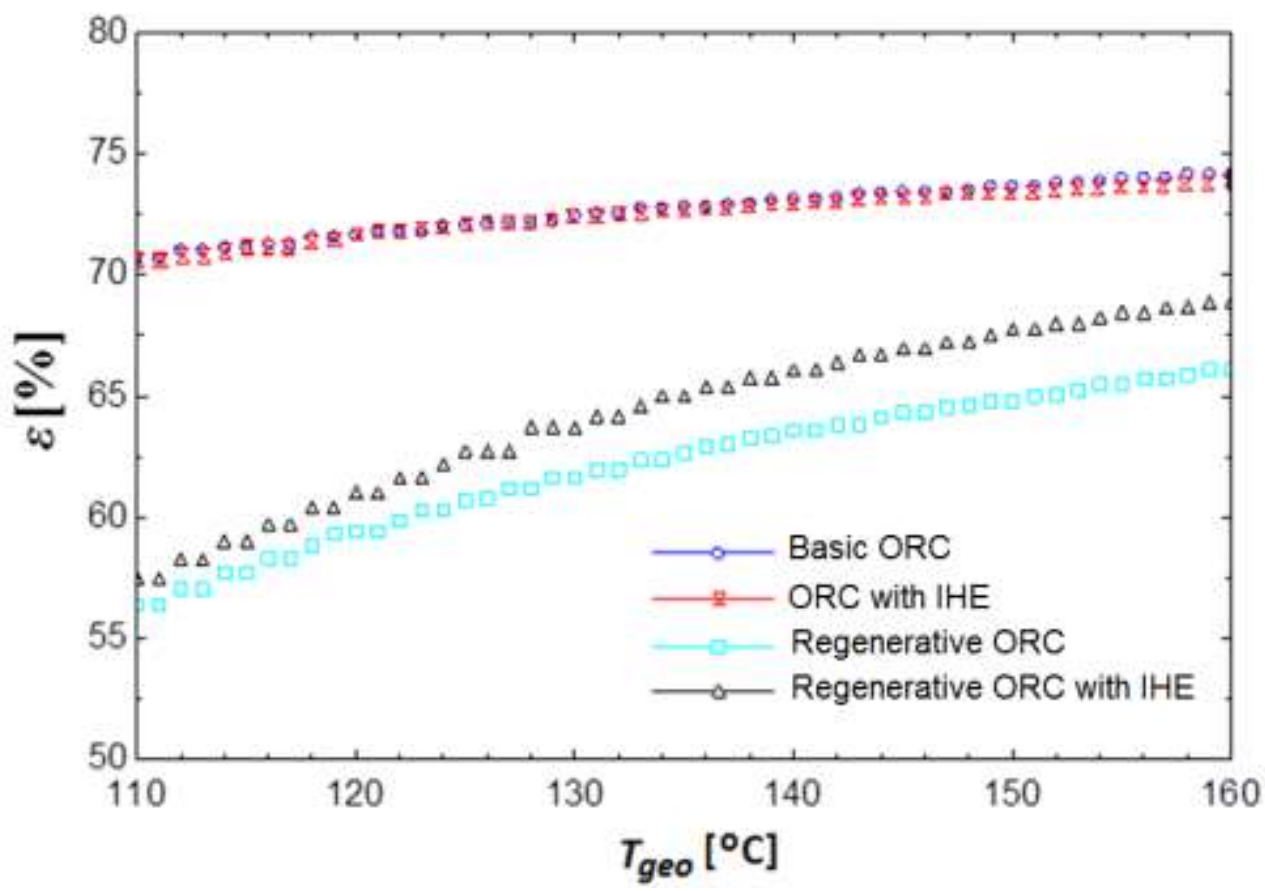

Figure 20: Cycle effectiveness at the optimum operating conditions, and with n-Pentane as organic binary fluid 


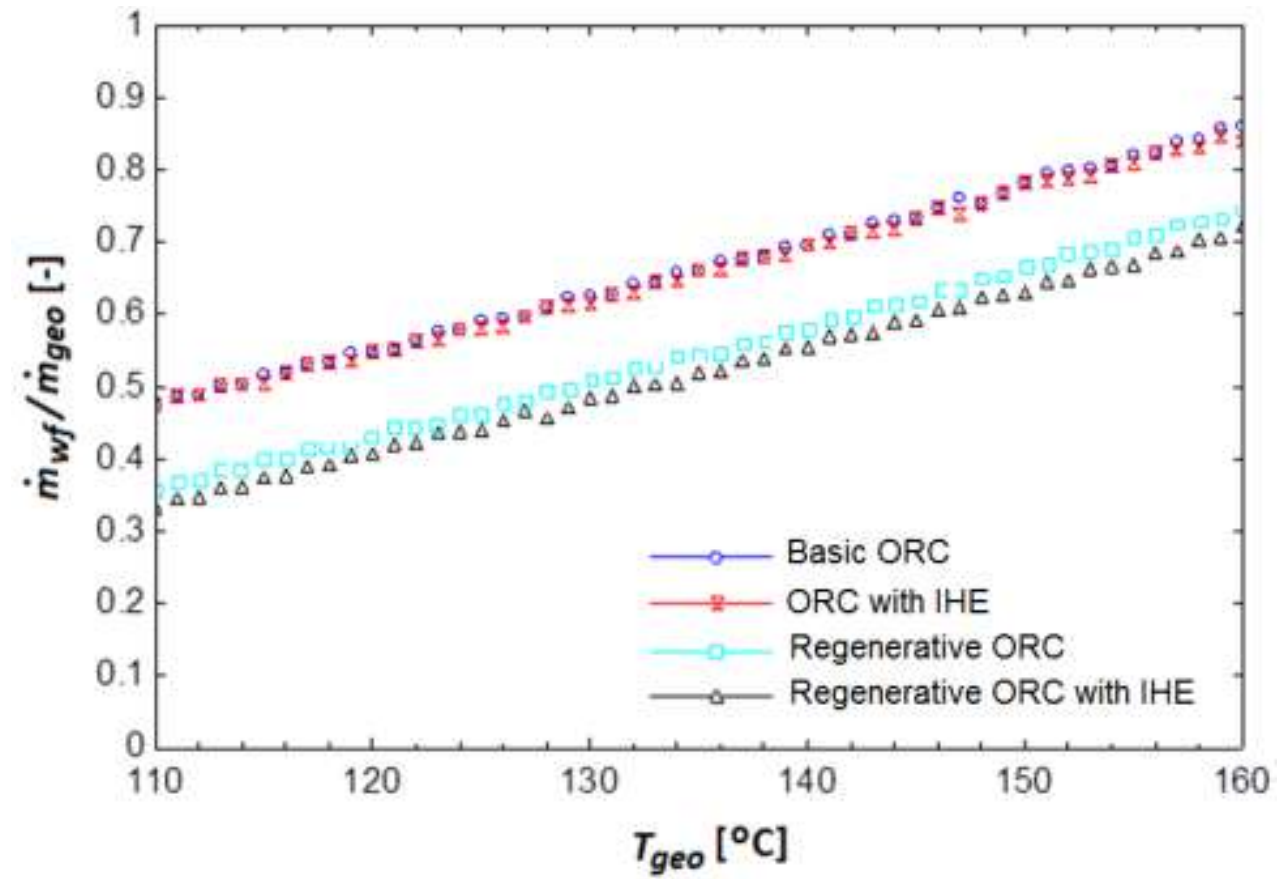

Figure 21: Ratio of mass flow rates, working fluid to geofluid, at the optimum operating conditions, and with n-Pentane as organic binary fluid 